Microwave assisted and conventional pyrolysis of MDF characterization of the produced biochars

Peer-reviewed author version

HAELDERMANS, Tom; Claesen, Joyce; MAGGEN, Jens; CARLEER, Robert; YPERMAN, Jan; ADRIAENSENS, Peter; SAMYN, Pieter; VANDAMME, Dries; CUYPERS, Ann; VANREPPELEN, Kenny \& SCHREURS, Sonja (2018) Microwave assisted and conventional pyrolysis of MDF - characterization of the produced biochars. In: JOURNAL OF ANALYTICAL AND APPLIED PYROLYSIS, 138, p. 218-230.

DOI: 10.1016/j.jaap.2018.12.027

Handle: http://hdl.handle.net/1942/27659 


\begin{tabular}{|c|c|}
\hline Citation & $\begin{array}{l}\text { T. Haeldermans, J. Claesen, J. Maggen, R. Carleer, J. Yperman, P. } \\
\text { Adriaensens, P. Samyn, D. Vandamme, A. Cuypers, K. Vanreppelen, S. } \\
\text { Schreurs } \\
\text { Microwave assisted and conventional pyrolysis of MDF - } \\
\text { characterization of the produced biochars } \\
\text { Journal of Analytical and Applied Pyrolysis 138C (2019) pp. 218-230 }\end{array}$ \\
\hline Archived version & $\begin{array}{l}\text { Author manuscript: the content is identical to the content of the published } \\
\text { paper, but without the final typesetting by the publisher }\end{array}$ \\
\hline Published version & https://doi.org/10.1016/j.jaap.2018.12.0270 \\
\hline Journal homepage & https://www.journals.elsevier.com/journal-of-analytical-and-applied-pyrolysis. \\
\hline Author contact & tom.haeldermans@uhasselt.be \\
\hline
\end{tabular}

(article begins on next page) 


\section{Microwave assisted and conventional pyrolysis of MDF - characterization of the produced biochars}

T. Haeldermans (a,b,d)*, J. Claesen (a), J. Maggen (a), R. Carleer (a), J. Yperman (a), P. Adriaensens (a), P. Samyn (a), D. Vandamme (a), A. Cuypers (c), K. Vanreppelen (a,d), S. Schreurs (b)

(a) Research Group of Analytical and Applied Chemistry, CMK, IMO, Hasselt University, Diepenbeek, Belgium

(b) Research Group of Nuclear Technology, CMK, Hasselt University, Diepenbeek, Belgium

(c) Research Group Environmental Biology, CMK, Hasselt University, Diepenbeek, Belgium

(d) Act \& Sorb, BVBA, Houthalen, Belgium

\section{Abstract}

Two different heat treatments for MDF, microwave assisted pyrolysis (MWP) and conventional pyrolysis (CPS), are investigated. The influence of different microwave absorbers (activated carbon (AC) and $\mathrm{K}_{2} \mathrm{CO}_{3}$ ) and different microwave powers in MWP and different temperatures in CPS on the characteristics of biochar is reviewed. This includes morphology and chemical properties of the obtained biochars are evaluated comparing biochar yield, ultimate analysis, proximate analysis, biochar stability test, FTIR spectroscopy and solid-state ${ }^{13} \mathrm{C}$ CP/MAS NMR spectroscopy. The resulting biochars of both processes are compared to find the best production method. An increasing microwave power without the use of MWA, leads to a higher degree of aromaticity. The addition of increasing amounts of $A C$ at low microwave power $(300 \mathrm{~W})$ leads to higher pyrolysis temperatures and more aromatic biochars. At $400 \mathrm{~W}$ a more aromatic biochar with a more open surface is achieved compared to $300 \mathrm{~W}$. However, the addition of an increasing amount of $A C$ as a MWA at $400 \mathrm{~W}$ induces a lower pyrolysis temperature with increasing biochar yields and decreasing aromaticity. $\mathrm{K}_{2} \mathrm{CO}_{3}$ is more effective as a MWA and produces more aromatic biochar at lower microwave power than when using AC. In general MWP yields a biochar with a higher degree of aromaticity at lower temperatures than CPS. Both CPS and MWP are viable options for transforming MDF into a value added biochar.

Key words: microwave assisted pyrolysis, microwave absorber, biochar, MDF, carbonization *Corresponding author: Tom Haeldermans, tom.haeldermans@uhasselt.be, Agoralaan gebouw D, 3590 Diepenbeek, Belgium. 


\section{Introduction}

Medium density fiberboard (MDF) is a lignocellulosic material made out of fresh pinewood and has a limited service life estimated around 10 years [1]. The world production of MDF in 2017 was $93.18 \mathrm{Mm}^{3}$, with Europe (46.5\%) as the major producer followed by Asia (39.0\%) [2]. Recycling of the panels is difficult as the size of the wood particles inside the board is very small and aminoplast resins are used, which cause the formation of toxic gases when combusted [3,4,5,6]. A sustainable solution is therefore required to avoid environmental problems and disposal costs. Conversion of these heterogeneous waste streams into a useable biochar or activated carbon (AC) can solve part of this problem, which is essential in the industrial society and critical to the development of a sustainable global circular economy $[7,8,9]$.

Lignocellulosic materials comprise out of cellulose, hemicellulose, lignin, extractives and a small fraction of inorganic matter. The thermochemical conversion of each component results in unique reaction pathways and therefore produces different reaction products [10]. A high content of cellulose and hemicellulose contribute to bio-oil yield, while a higher lignin content increases the average solid char yield [11]. Interactions between these components during pyrolysis have, however, been confirmed in previous research. This makes predictions of the thermal behaviour of the material very difficult $[11,12]$.

Thermochemical conversion processes include direct combustion, gasification, liquefaction and pyrolysis [13]. Pyrolysis is the thermal degradation process in an oxygen deficient atmosphere to produce char and variety of gaseous and condensable (bio-oil) products [14]. It is generally accepted that pyrolysis consists of three main stages: (i) initial evaporation of free water, (ii) primary decomposition and (iii) secondary reactions such as oil cracking and repolymerisation [11]. The required heat for these reactions is provided by direct or indirect heating in conventional pyrolysis (CPS). The heat is transferred directly to the particle surface through convection from the pyrolysis oven and it is then further transferred from the outside of the particle to the inside through conduction. The temperature gradient is therefore from the outside of the particle to the inside, while the released volatiles diffuse from the inside to the outside of the particle [15].

In recent years microwave assisted pyrolysis (MWP) was proven to be a promising alternative to CPS. Microwave systems show a distinct advantage in providing a fast, energy-efficient, and selective heating process compared to CPS, therefore facilitating increased production rates and decreased production costs[14, 16]. In contrary to CPS, in MWP there is no physical contact between the biomass and the heating source, instead microwaves penetrate the sample and the energy is transformed to thermal energy within the particle. This happens as a result of changing ions and dipoles in the material in the direction of the microwaves that hit the sample [17].This energy is transported outwards, which results in a temperature gradient from the inside to the outside of the particle, which is the same direction as for the released volatiles [15]. Using lignocellulosic materials for MWP proves to be difficult since these materials are usually low microwave absorbers (MWA's). However, by adding a MWA, these materials can indirectly heat the surrounding particles, influencing the yield of the different end products like biochar and their quality [14]. Biochar is the solid, carbon rich product that is obtained by the thermochemical conversion of lignocellulosic materials through pyrolysis at moderate temperature. It has the potential to improve soil fertility and soil physical properties by, among other things, increasing the soil nutrient and water retention, elevating soil pH and improving microbial activity $[16,17]$. Biochar made from organic waste also works as an effective carbon sink for hundreds to thousands of years, since it stores carbon that was captured as $\mathrm{CO}_{2}$ by plants $[18,19]$. In order for the biochar to remain stable in the soil, aromaticity is a very important indicator. A higher degree of aromaticity indicates a more stable biochar and therefore a better carbon sink [22]. Biochars with a high level of aromatic structures are also known to be better adsorbents than biochar with a low degree of aromaticity [23]. As aromaticity increases, the carbon structure gets more condensed and less nutrients are available, suggesting a lower contribution to soil fertility [23]. When the biochar is used as a fertilizer it is not necessarily favourable to have a high level of aromaticity. 
When the biochar is used as an adsorbent or as a precursor for activated carbon, the aromatic fraction should be as high as possible.

Several parameters such as reactor type, sample size, pressure, temperature, power, residence time, flow of carrier gas and the use of a MWA should be considered for the optimization of the desired pyrolysis products [22,23]. While MWP is still a novel technique, a lot of research has already been done on this topic [15,24,25]. Subjects like the effects of different MWA on the pyrolysis process, the effect of different feedstock properties on the pyrolysis process and the technical and economic principles behind the microwave pyrolysis process itself are already researched. A problem occurs however when considering different feedstock types. Since every lignocellulosic material is unique it will always react differently in the pyrolysis process [17]. The microwave pyrolysis of MDF with the aim to produce biochar in the most effective way, both technically and economically, has not been done before. MDF is a problematic waste stream for which a viable solution is needed. In this article two different possible solutions for MDF (MWP and CPS) are investigated. The influence of different microwave absorbers and different microwave powers in MWP and different temperatures in CPS on the characteristics of biochar is reviewed. Furthermore, the characterization of this biochar, especially with ${ }^{13} \mathrm{C}-\mathrm{NMR}$ spectroscopy, is a novelty. At last, a comparison between both pyrolysis techniques for the same input material is very useful when considering new valorization methods.

\section{Material and Methods \\ 2.1 Medium density fibreboard}

MDF was used as lignocellulosic material. This material is composed out of pinewood fibres which are pressed and glued together with additives (<10\%) like urea formaldehyde (UF) and melamine urea formaldehyde (MUF). When no MWA was added, MDF sawdust was used. In case of adding a MWA, MDF pellets were used to have a better mixing of the materials and to avoid the formation of hotspots. The MDF pellets have a diameter of $5 \mathrm{~mm}$ and lengths varying between 5 and $20 \mathrm{~mm}$. The MDF pellets were grinded when used with $\mathrm{K}_{2} \mathrm{CO}_{3}$ because the granular nature of the $\mathrm{K}_{2} \mathrm{CO}_{3}$ caused the product to slump to the bottom of the reactor tube. This meant that there was no sufficient contact between the MWA and the MDF material, causing the material to not heat up sufficiently. Since the AC powder sticks to the MDF pellets, sufficient heat transfer was obtained and the pellets did not have to be grinded.

\subsection{Microwave absorbers}

Activated carbon (AC) (Chemviron Carbon, Pulsorb WP 260) and analytical grade potassium carbonate $\mathrm{K}_{2} \mathrm{CO}_{3}$ (Merck, Art. 4928) were used as MWA's. Due to the granular nature of $\mathrm{K}_{2} \mathrm{CO}_{3}$, it was first grinded prior to adding to the grinded MDF pellets (figure 1b). In de case of AC, MDF pellets were not grinded (figure 1a). The particle size of the major fraction of the activated carbon (AC) (65-85 wt.\%) is less than 325 mesh. $\mathrm{AC}$ and $\mathrm{K}_{2} \mathrm{CO}_{3}$ are both widely used as a MWA since they are non-toxic and easy to remove [27].

\subsection{Microwave pyrolysis}

Without the use of any MWA, MWP was performed on $40 \mathrm{~g}$ of MDF, weighed into a microwave tube, using a Milestone ROTO SYNTH Rotative Solid Phase Microwave Reactor, with a tilted and rotating reactor with a volume of $300 \mathrm{~mL}$ (Milestone Srl., Sorisole, Italy). MWP was carried out under reduced pressure (40-80 mbar) and fixed microwave power $(750,1000$ or $1250 \mathrm{~W})$ under a $\mathrm{N}_{2}$ flow $(90 \mathrm{~mL} / \mathrm{min})$ for 30 minutes and an operating frequency of $2.45 \mathrm{GHz}$. The reactor is connected to a vacuum pump with a maximum flow of $2.0-2.3 \mathrm{~m}^{3} / \mathrm{h}$ to ensure the reduced pressure in the reactor vessel. The settings of this pump remained the same during all experiments. The nitrogen flow in MWP is only used to flush the reactor at the start of the experiment and to make sure that no residual air is left in the reactor vessel. Temperature inside the cavity was constantly measured via an infrared detector. In the MWP experiments with MWA, AC and $\mathrm{K}_{2} \mathrm{CO}_{3}$ were separately added in powder form at $3 \%, 5 \%$ and $10 \%$ of the MDF pellets weight and agitated well to maximize the contact of the MWA with the MDF pellets (figure 1Figure 
1). For safety reasons, the sample weight was reduced to $20 \mathrm{~g}$ per batch, since abundant gas formation can cause damage to the top of the reactor. Microwave pyrolyses were carried out in the same reactor in reduced pressure (400-700 mbar) and at a microwave power of 300 and $400 \mathrm{~W}$ (only with AC), using a step-by-step heating program of one minute of heating and a 30 seconds rest period under a $\mathrm{N}_{2}$ flow of $90 \mathrm{~mL} / \mathrm{min}$ for 37.5 minutes in total. It was found that experiments at a power of $400 \mathrm{~W}$ led to the phenomenon of electric arcing caused by the interaction of the formed metallic potassium with high energy microwaves [28]. Since the temperatures of these hot spots are much higher than the temperature in bulk material, it causes electric arcing and undesired reactions, damaging the reactor [28]. Therefore only $300 \mathrm{~W}$ experiments were done for $\mathrm{MDF}$ with $\mathrm{K}_{2} \mathrm{CO}_{3}$. All microwave pyrolysis experiments with MWA were carried out twice.
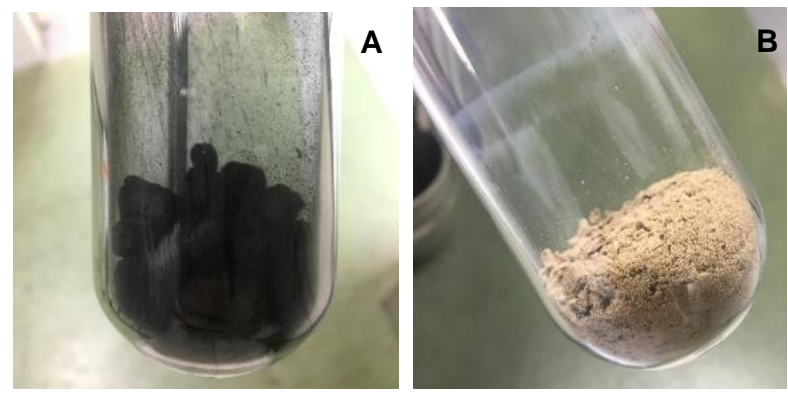

Figure 1: MDF pellets mixed with $\mathrm{AC}(\mathrm{a})$ and MDF pellets mixed with $\mathrm{K}_{2} \mathrm{CO}_{3}(\mathrm{~b})$.

\subsection{Conventional pyrolysis}

The pyrolysis reactor that was used to produce biochar at 350 and $450{ }^{\circ} \mathrm{C}$ is an own-build reactor (figure 2) and manufactured in stainless steel (AISI 304), with a volume of around $290 \mathrm{~cm}^{3}$, which relates to 40 grams of maximum input. The reactor consists of a rotating, hollow screw (1), which is powered by an electric motor (2) to ensure uniform heating of the char during the process. The temperature and heating rate of the biomass and char is measured by a thermocouple type $\mathrm{K}(3)$ and is regulated by a pre-programmed FGH 1000 controller (4) which drives a "Nabertherm" furnace (5) [9]. The reactor is constantly flushed with $70 \mathrm{~mL} / \mathrm{min}$ of nitrogen gas (6). The heating rate of the oven was set at $15^{\circ} \mathrm{C} / \mathrm{min}$. Once the working temperature is reached, an isothermal period of 30 minutes is applied before the reactor is cooled down to room temperature. The char yield of pyrolysis is calculated by dividing the mass of the char that is obtained after pyrolysis by the mass of the biomass that is injected into the reactor before pyrolysis. All CPS experiments were carried out in threefold.

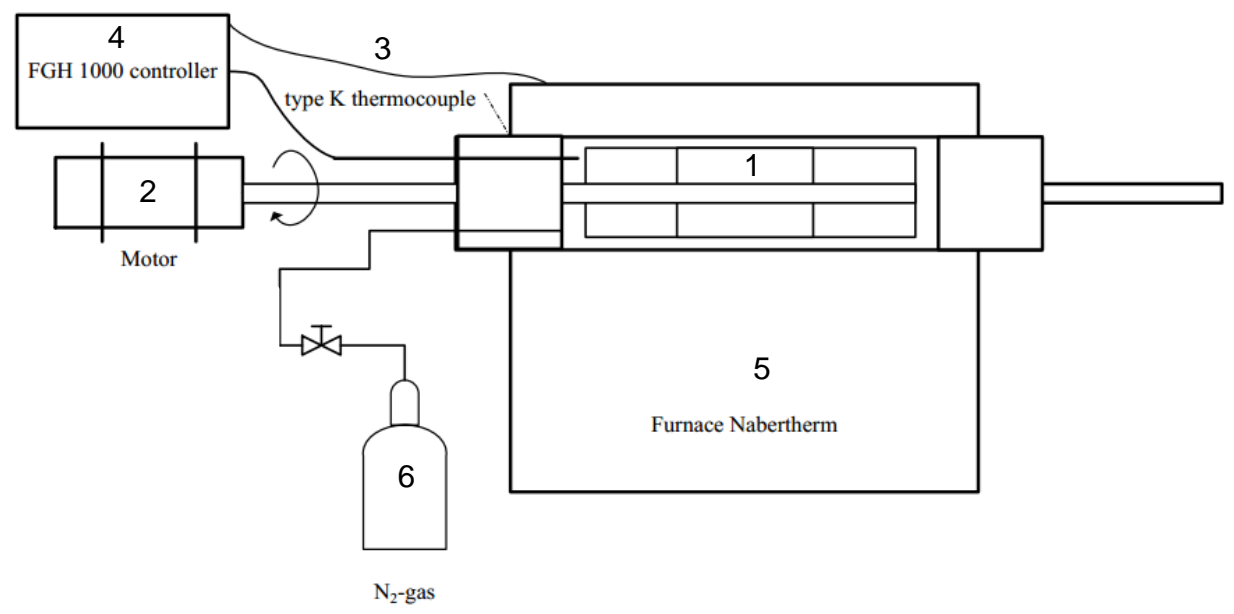

Figure 2: Schematic representation of the pyrolysis reactor [9]

\section{Characterization \\ 3.1 Pre-treatment}


Prior to analysis MDF was grinded and homogenized by using a ball mill (Retsch S1 planetary ball mill). Biochar obtained from MWP without MWA was grinded and homogenized (ball mill). Biochar obtained from MWP with addition of $A C$, was first sieved ( 35 mesh) to remove the $A C$ and then homogenized (same treatment). When $\mathrm{K}_{2} \mathrm{CO}_{3}$ was added as MWA, the obtained biochar was washed with Milli-Q water to remove the excess $\mathrm{K}_{2} \mathrm{CO}_{3}$ and formed $\mathrm{K}_{2} \mathrm{O}$ and $\mathrm{K}$. The residues were dried $\left(105^{\circ} \mathrm{C}\right)$ and grinded up into a fine powder. All analyses were done using the fraction below $63 \mu \mathrm{m}$. yields are calculated after the removal of MWA's.

\subsection{Proximate analysis}

Thermogravimetric analysis (TGA) was performed (TA Q500, Zellik, Belgium) using the following temperature and temperature program: heating from room temperature to $600{ }^{\circ} \mathrm{C}$ at a heating rate of $20{ }^{\circ} \mathrm{C} / \mathrm{min}$ under $90 \mathrm{~mL} / \mathrm{min} \mathrm{N}_{2}-$ flow and switching at $600{ }^{\circ} \mathrm{C}$ to $90 \mathrm{~mL} / \mathrm{min} \mathrm{O}_{2}$-flow until $900{ }^{\circ} \mathrm{C}$ was reached using the same heating rate. Sample size was $\pm 5 \mathrm{mg}$. Moisture, volatile matter, fixed carbon and ash content were determined.

\subsection{Ultimate analysis}

Total carbon, hydrogen, nitrogen and sulphur content of all samples were determined in quadruplicate using a Thermo Electron Flash EA1112 elemental analyser (Thermo Electron, Waltham, USA). Sample size was around 2 mg. Calibration was carried out using BBOT (2,5-bis (5-tert-butyl-benzoxazol-2-yl) thiophene). Ash was determined by TGA and $\mathrm{O}$ was calculated by difference $(\mathrm{O}=100 \%-\mathrm{C} \%-\mathrm{H} \%-\mathrm{N} \%-$ Ash $\%)$. No sulphur was detected.

\subsection{Stability test}

The relative long-term stability of the biochars was determined by adding a calculated weight of biochar (equivalent of $0.1 \mathrm{~g}$ of carbon, approximately $0.15 \mathrm{~g}$ of sample) to $7 \mathrm{~mL}$ hydrogen peroxide (5\%). The mixtures were heated for 48 hours at $80^{\circ} \mathrm{C}$ and occasionally stirred. Afterwards, the samples were dried at $105^{\circ} \mathrm{C}$. Element analysis was carried out before and after oxidation. The biochar stability was calculated using the following equation:

Biochar stability $(\%)=\frac{B_{a} \times \% C_{a}}{B_{b} \times \% C_{b}} \cdot 100$

Where $\mathrm{B}_{\mathrm{a}}$ is the mass of biochar after oxidation, $\% \mathrm{C}_{\mathrm{a}}$ is the carbon in wt.\% after oxidation (determined by element analysis), $\mathrm{B}_{\mathrm{b}}$ is the initial mass of biochar and $\% \mathrm{C}_{b}$ is the carbon in wt. \% before oxidation (determined by element analysis) [29,30].

\subsection{Fourier transform infrared analysis (FT-IR)}

FT-IR spectra of biochars and biomass were obtained using a spectrophotometer model VERTEX 70 FTIR Spectrometer equipped with a DTGS detector, FT-IR microscope (Hyperion 2000 equipped with MTC detector) and ATR accessory (Ge crystal) (Bruker, Karlsruhe, Germany). The transmittance of the different biochars was measured in the wavenumber interval of $4000-600 \mathrm{~cm}^{-1}$. The resolution of the spectra is $4 \mathrm{~cm}^{-1} .32$ scans were acquired per sample. MDF biomass and the char produced with CPS were measured in ATR mode, while the biochars produced with MWA are measured in transmittance ( $\mathrm{KBr}$ pellets). All spectra were baseline corrected and normalised at $3300 \mathrm{~cm}^{-1}$.

\subsection{Scanning electron microscopy (SEM)}

Morphology of the biochar was evaluated by using TM3000 Table top Scanning Electron Microscope (Hitachi, Krefeld, Germany). Samples were gold sputter coated using jfc-1300 auto fine coater (Jeol, Tokio, Japan) for 60 seconds at $30 \mathrm{~mA}, 0.05 \mathrm{mbar}$ and a working distance of $4 \mathrm{~cm}$. SEM was performed at $15 \mathrm{kV}$ on the following samples: biochar produced with MWP at $300 \mathrm{~W}$ with $10 \% \mathrm{AC}$, biochar produced with MWP at $400 \mathrm{~W}$ with $3 \% \mathrm{AC}$, biochar produced at $300 \mathrm{~W}$ with $10 \% \mathrm{~K}_{2} \mathrm{CO}_{3}$, biochar produced with $\mathrm{CPS}$ at $450{ }^{\circ} \mathrm{C}$ and MDF biomass.

\subsection{High-resolution ${ }^{13} \mathrm{C}$ solid-state NMR}

Carbon-13 solid-state CP/MAS (Cross-Polarization/Magic Angle Spinning) NMR spectra were acquired on a Bruker Avance $400 \mathrm{MHz}$ spectrometer (9.4 T wide bore magnet) equipped with a $4 \mathrm{~mm} \mathrm{BL4} \mathrm{X/Y/H}$ probe. Magic angle spinning was performed at $13 \mathrm{kHz}$ using ceramic rotors of $4 \mathrm{~mm}$ in diameter. The aromatic signal of 
hexamethylbenzene was used to determine the Hartmann-Hahn condition $\left(\omega_{1 H}=\gamma_{\mathrm{H}} \mathrm{B}_{1 \mathrm{H}}=\gamma_{\mathrm{C}} \mathrm{B}_{1 \mathrm{C}}=\omega_{1 \mathrm{C}}\right)$ for crosspolarization and to calibrate the carbon chemical shift scale (132.1 ppm). Acquisition parameters used were the following: a spectral width of $50 \mathrm{kHz}$, a $90^{\circ}$ pulse length of $3.6 \mu \mathrm{s}$, a spin-lock field for cross-polarization of $50 \mathrm{kHz}$, a contact time for cross-polarization of $1.5 \mathrm{~ms}$, an acquisition time of $15 \mathrm{~ms}$, a recycle delay time of $5 \mathrm{~s}$ and about 12000 accumulations. High power proton dipolar decoupling during the acquisition time was set to $80 \mathrm{kHz}$. Solidstate NMR was carried out on biochar produced by MWP at $750 \mathrm{~W}$ and $1250 \mathrm{~W}$, by MWP with AC (3 and $10 \%)$ as MWA at 300 and $400 \mathrm{~W}$, by MWP with $\mathrm{K}_{2} \mathrm{CO}_{3}\left(3\right.$ and $10 \%$ ) as MWA at $300 \mathrm{~W}$ and by CPS at $350{ }^{\circ} \mathrm{C}$ and $450{ }^{\circ} \mathrm{C}$. Carbonyl $\mathrm{C}$, aromatic $\mathrm{C}$ and aliphatic $\mathrm{C}$ were determined by dividing the peak area of the fixed chemical shift region by the total peak area [31], [32].

\section{Results and discussion}

Biochar was produced using different pyrolysis techniques and different pyrolysis parameters to find the optimal conditions for the production of biochar.

\subsection{Biochar production}

The temperature profiles for both MWP and CPS are found in figure 3. Multiple studies have reported that pyrolysis reactions occur at lower temperatures in MWP then in CPS [33-35]. Therefore, it can be seen from figure 3 that all temperature profiles from MWP have a lower maximum temperature than the maximum temperature from CPS.

Temperature profiles for the MWP's using different process parameters can be found in figure 3 . The MWP process without the use of MWA's (figure 3A) can be dived into two stages. In the first stage there is a gradual temperature rise until thermal equilibrium is reached. Heating rate and final temperature $\left(175^{\circ} \mathrm{C}\right.$ to $\left.215^{\circ} \mathrm{C}\right)$ increases as MWP increases from $750 \mathrm{~W}$ to $1250 \mathrm{~W}$.

MWP at $300 \mathrm{~W}$ with AC as MWA (figure 3B) shows the same temperature profile as the MWP without MWA. The final pyrolysis temperature is higher and varies from $225^{\circ} \mathrm{C}$, to $260^{\circ} \mathrm{C}$ and $315^{\circ} \mathrm{C}$. This observation was also found by Antunes et al. [20]. Furthermore a higher heating rate was also observed with increasing AC amount. Higher temperature and heating rate are caused by indirect heating of the surrounding particles by the AC.

When using $A C$ as a MWA at a higher power of $400 \mathrm{~W}$, a higher maximum pyrolysis temperature was achieved (figure $3 \mathrm{C}$ ). Temperatures around $385{ }^{\circ} \mathrm{C}$ were reached when 3 and $5 \%$ of $\mathrm{AC}$ was added. Although the maximum temperature is similar, the material is exposed to a higher temperature for a longer time when $3 \%$ of $\mathrm{AC}$ was added starting from a residence time of $25 \mathrm{~min}$. A lower maximum temperature of $310^{\circ} \mathrm{C}$ was observed early in the process when $10 \%$ of $A C$ was added. The seemingly contradicting results of a decreasing temperature when adding more MWA might be explained by the fact that the high percentage of AC causes a steeper heating rate, leading to the occurrence of non-equilibrium reactions early in the process [36]. Another reason is the high temperature difference between the ambient and the material temperature, causing heat loss [36]. Additionally, there was a high gas and oil production at the beginning of the process due to this high heating rate (figure $3 \mathrm{C}$ ). This removes a lot of heat from the process, leading to a lower final temperature and therefore a higher biochar yield. Indeed optimal pyrolysis conditions are already reached when only $3 \%$ of $A C$ is added, which is beneficial from an economical perspective. Using $\mathrm{K}_{2} \mathrm{CO}_{3}$ as a MWA, the temperature profile changes completely. Four stages can be distinguished in the MWP with $\mathrm{K}_{2} \mathrm{CO}_{3}$ (figure $3 \mathrm{D}$ ): the first stage where the temperature rises from room temperature to around $100{ }^{\circ} \mathrm{C}$; the second stage where the temperature reached a plateau before attaining the pyrolysis temperature, also called the pre-pyrolysis stage; the third stage where the temperature rises very fast corresponding to the loss of mass, known as the pyrolysis stage; and the final stage: the thermal equilibrium [37]. It should be noted that when only $3 \%$ of $\mathrm{K}_{2} \mathrm{CO}_{3}$ is added, the MWA is not able to absorb enough microwave energy to sufficiently increase the temperature of the overall mixture. A significant increase in maximum temperature from $190{ }^{\circ} \mathrm{C}$ to $335{ }^{\circ} \mathrm{C}$ and $340{ }^{\circ} \mathrm{C}$ was observed when the ratio of $\mathrm{K}_{2} \mathrm{CO}_{3}$ was increased from $3 \%$ to $5 \%$ and $10 \%$ respectively.

$\mathrm{K}_{2} \mathrm{CO}_{3}$ can undergo reduction in inert atmosphere to form $\mathrm{K}, \mathrm{K} 2 \mathrm{O}, \mathrm{CO}$ and $\mathrm{CO}_{2}$ in the following reactions [38,39]: 
$\mathrm{K}_{2} \mathrm{CO}_{3}+2 \mathrm{C} \leftrightarrows 2 \mathrm{~K}+3 \mathrm{CO}$

$\mathrm{K}_{2} \mathrm{CO}_{3} \leftrightarrows \mathrm{K}_{2} \mathrm{O}+\mathrm{CO}_{2}$

$\mathrm{K}_{2} \mathrm{CO}_{3}+2 \mathrm{C} \leftrightarrows 2 \mathrm{~K}+3 \mathrm{CO}$

High pyrolytic temperature promotes $\mathrm{C}-\mathrm{K}_{2} \mathrm{CO}_{3}, \mathrm{C}-\mathrm{K}_{2} \mathrm{O}$ and $\mathrm{C}-\mathrm{CO}_{2}$ reactions, which enables the elimination and breaking of C-O-C and C-C bonds causing a decrease in biochar yield [33,35]. It is suggested that $\mathrm{K}_{2} \mathrm{CO}_{3}$ is performing bad as a MWA at low temperatures and that heat and mass transfer resistance is enhanced with the addition of $\mathrm{K}_{2} \mathrm{CO}_{3}$ at low temperatures. This is why pyrolysis reactions are postponed and reaction temperature is low at $3 \%$ of $\mathrm{K}_{2} \mathrm{CO}_{3}[41,42]$.

In conventional pyrolysis the MDF was heated up at $15^{\circ} \mathrm{C}$ per minute until the set pyrolysis temperature $\left(350{ }^{\circ} \mathrm{C}\right.$ or $450{ }^{\circ} \mathrm{C}$ ) was reached. Due to the slow reaction time and thermal inertia of the electrical furnace, there are a few inconsistencies with the theoretically expected temperature profile. At the start there is a period of about 6 minutes where the furnace heats up very slowly, after this there is a period where the furnace is heated up very fast until the heating rate of $15^{\circ} \mathrm{C} / \mathrm{min}$ is reached. When the set pyrolysis temperature is reached, there is an overshoot of around $40{ }^{\circ} \mathrm{C}$ before the furnace cools down again to the set pyrolysis temperature. After this an isothermal period of 30 minutes was introduced as can be seen in figure $3 \mathrm{E}$. The mean temperature of this isothermal period is $350{ }^{\circ} \mathrm{C}$ and $450{ }^{\circ} \mathrm{C}$ respectively. Because of the identical heating rate and isothermal period, the residence time of the MDF in the reactor is slightly higher when produced at $4500^{\circ} \mathrm{C}$ than at $350{ }^{\circ} \mathrm{C}$.
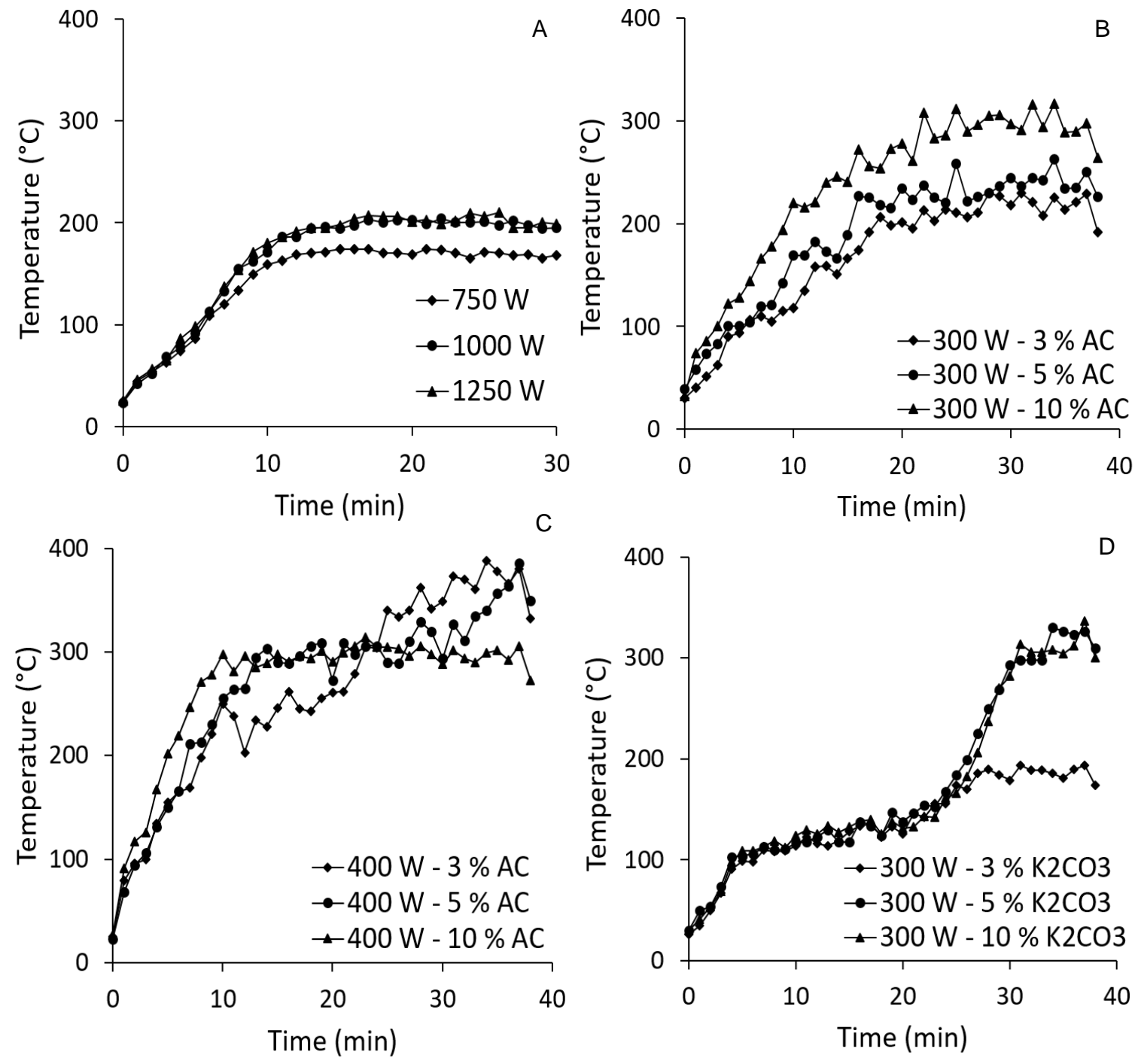


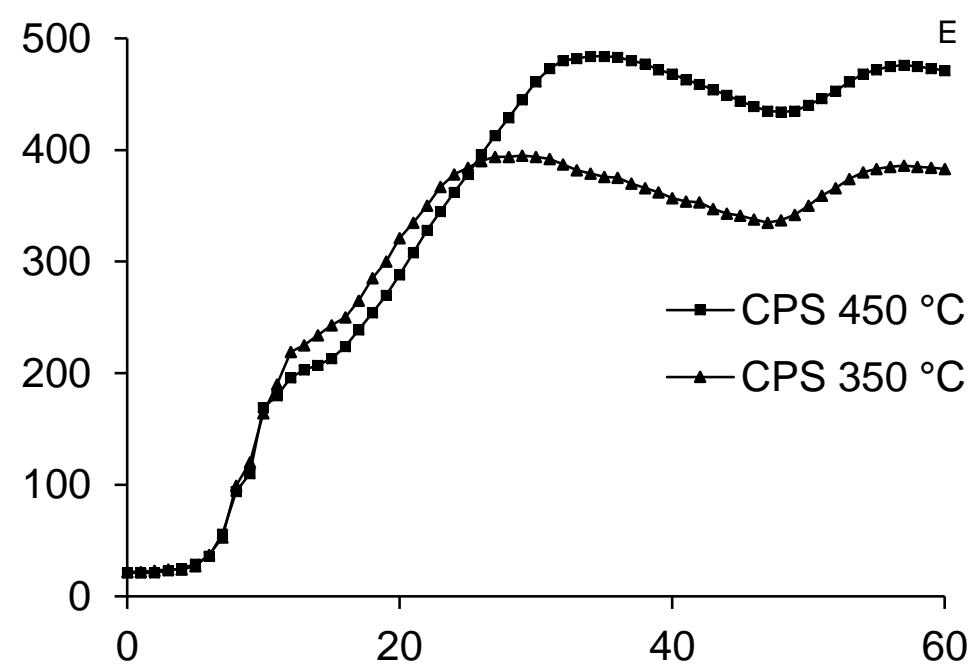

Figure 3: Temperature profiles of MWP of MDF with different percentages of MWA added; A: no MWA, B: 300 W and a varying amount of $A C, C: 400 \mathrm{~W}$ and a varying amount of $\mathrm{AC}, \mathrm{D}: 300 \mathrm{~W}$ and a varying amount of $\mathrm{K}_{2} \mathrm{CO}_{3}, \mathrm{E}$ : CPS at $350^{\circ} \mathrm{C}$ and $450{ }^{\circ} \mathrm{C}$

\subsection{Biochar chemical characterization}

Biochars obtained from MWP and CPS are analysed and compared to each other. All analysed chemical characteristics of the biochars can be found in table 1 .

\subsection{Microwave pyrolysis characterization \\ 4.3.1 MWP without MWA}

When microwave power was increased from $750 \mathrm{~W}$ to $1000 \mathrm{~W}$ and $1250 \mathrm{~W}$ without the addition of a MWA, a similar biochar yield was obtained (table 1). However, the conversion of MDF was not completed, probably because of the low maximum temperature reached (figure $3 \mathrm{~A}$ ), which was not high enough for complete thermo-chemical conversion of MDF. Fixed carbon and biochar stability increases, while volatile matter decreases as MW power increases. These results indicate a higher aromaticity when a higher microwave power is applied without the use of a MWA. Enhanced aromaticity is due to dehydration, decarboxylation and cyclization reactions $[24,25]$.

\subsubsection{MWP with $\mathrm{AC}$ at $300 \mathrm{~W}$}

The ratio of MWA to MDF was assumed to play a crucial factor on biochar characteristics [43]. Therefore characteristics after adding AC were evaluated. First, a decrease in biochar yield was observed when the amount of $A C$ was increased (table 1). A possible explanation for this observation is the increase of pyrolysis temperature and heating rate as more $\mathrm{AC}$ is added (figure $3 \mathrm{~B}$ ). Carbon content reaches a maximum at $5 \% \mathrm{AC}$ addition, while hydrogen content decreases when $3 \%$ and $5-10 \%$ of $A C$ is added respectively. Volatile matter reaches a minimum, while fixed carbon reaches a maximum value at $5 \%$ MWA addition. $\mathrm{H} / \mathrm{C}$ ratio decreases and biochar stability increases by increasing the amount of MWA. Therefore, it can be concluded that biochar becomes more aromatic when adding a higher percentage of $A C$ at a microwave power of $300 \mathrm{~W}$, due the increased reaction temperature [44].

\subsubsection{MWP with AC at $400 \mathrm{~W}$}

Increasing the microwave power up to $400 \mathrm{~W}$ using $\mathrm{AC}$ as MWA, an increase in biochar yield was observed when the amount of AC was increased (Table 1). As more AC was added, the biochar yield, biochar stability and carbon content decreased while the nitrogen, oxygen and hydrogen content increased. At $10 \% \mathrm{AC}$ addition a much higher remaining volatile content is observed with the lowest fixed carbon content (Table 1). The increasing $\mathrm{H} / \mathrm{C}$ ratio when AC content is increased is supported by a decreasing biochar stability, indicating a lower aromaticity.

\subsubsection{MWP with $\mathrm{K}_{2} \mathrm{CO}_{3}$ at $300 \mathrm{~W}$}


When an alkali metal-ion based MWA was added, biochar yield decreased dramatically when the ratio of $\mathrm{K}_{2} \mathrm{CO}_{3}$ increased from $3 \%$ to $5 \%$ and $10 \%$ (Table 1). Comparing the results of the biochar produced at $300 \mathrm{~W}$ with $5 \%$ and $10 \%$ of $\mathrm{K}_{2} \mathrm{CO}_{3}$ with the results of the biochar produced with $\mathrm{AC}$ at $300 \mathrm{~W}$, a lower biochar yield, higher fixed carbon content, lower volatile matter, higher $\mathrm{H} / \mathrm{C}$ ratio and higher stability were obtained when the same amount of MWA was added. $\mathrm{K}_{2} \mathrm{CO}_{3}$ is a strong polar material and has a dielectric constant of around 2.5 at $2.45 \mathrm{GHz}$ at the observed temperatures [45]. $\mathrm{K}_{2} \mathrm{CO}_{3}$ can therefore strongly absorb microwaves, resulting in a high temperature inside biomass. Therefore more non-condensable gases are generated (figure 3D) as described in section 4.1. Furthermore, $\mathrm{K}_{2} \mathrm{CO}_{3}$ can also act as an in-situ catalyst as described in section 4.3.1. The presence of $\mathrm{K}_{2} \mathrm{CO}_{3}$ therefore causes an increase in reaction temperature and a higher biochar yield as a result of $\mathrm{K}$, which facilitates the decomposition of the MDF and the generation of the biochar. This increase in biochar yield in comparison with $\mathrm{AC}$ as a MWA can be seen in table 1.[41]

Carbon content increases when a higher amount of $\mathrm{K}_{2} \mathrm{CO}_{3}$ is added. Hydrogen content decreases as carbon content increases when $3 \%$ and $5 \%$ of $\mathrm{K}_{2} \mathrm{CO}_{3}$ is added respectively, explaining the very high stability of the biochar with $5 \%$ of $\mathrm{K}_{2} \mathrm{CO}_{3}$. Hydrogen content increases again when $10 \%$ of $\mathrm{K}_{2} \mathrm{CO}_{3}$ is added, which is also demonstrated in a slight decrease in biochar stability. Fixed carbon content increases and volatile matter decreases with an increasing amount of MWA. This is in accordance to the increasing carbon content and the decreasing oxygen content (table 1). Optimal pyrolysis conditions are reached when $5 \%$ of $\mathrm{K}_{2} \mathrm{CO}_{3}$ is added, meaning that more than $5 \%$ of $\mathrm{K}_{2} \mathrm{CO}_{3}$ does not lead to additional advantages (e.g. more aromaticity).

\subsection{Comparison with conventional pyrolysis}

As discussed for MWP, the lower char yield at higher pyrolysis temperatures is due to the higher amount of volatiles produced at higher pyrolysis temperatures. This is also the case for CPS (table 1). A more complete pyrolysis at a higher temperature is demonstrated by the lower amount of nitrogen, hydrogen, carbon and remaining volatile matter. A higher amount of fixed carbon is found for the biochar produced at $450{ }^{\circ} \mathrm{C}$ (table 1). A decrease in hydrogen content is found for the char produced at $450{ }^{\circ} \mathrm{C}$, the therefore lower $\mathrm{H} / \mathrm{C}$ ratio and higher stability is indicating a higher degree of aromatization than for the biochar produced at $350^{\circ} \mathrm{C}$.

Compared to the MDF biomass, the carbon content increases significantly in the biochar from CPS, while hydrogen and oxygen content decreases significantly, indicating aromatization. Nitrogen content, however increases, indicating that it is incorporated in the carbon structure (table 1). Comparing the results of MWP without MWA to CPS, it is clear that a less complete carbonization is achieved which can be attributed to the lower pyrolysis temperatures. Nitrogen is retained to a lower degree than in CPS (table 1). Because of the lower temperatures when $300 \mathrm{~W}$ is applied in MWP compared to CPS, carbonization is again less complete in MWP. This leads to a biochar that is less aromatic and therefore less stable.

When the results of the biochar produced at $400 \mathrm{~W}$ with $3 \%$ and $5 \% \mathrm{AC}$ are compared to those of CPS, it can be seen that the $\mathrm{H} / \mathrm{C}$ ratio of the char from MWP is a lot higher for comparable pyrolysis temperatures. The biochar stability in the chars produced with MWP is also elevated. These results indicate that the degree of aromatization is higher in the biochar from MWP. It is also clear that for the same amount of fixed carbon, the biochar yield is higher in CPS. An explanation for this could be a more open surface structure which is achieved when $400 \mathrm{~W}$ is applied with AC as a MWA compared to CPS, as can be seen with SEM (see further).

Although the yield of the biochars (at $5 \%$ and $10 \% \mathrm{~K}_{2} \mathrm{CO}_{3}$ with MWP) is comparable to those of the CPS, the total and fixed carbon content is considerably lower as can be seen in table 1 . This can be explained by the following gasification reaction, which is enhanced by the presence of $\mathrm{K}$ [41]. This reactive $\mathrm{CO}_{2}$ atmosphere in the reaction vessel can also have an effect on the carbonous structure of the biochar.

$\mathrm{C}(\mathrm{s})+\mathrm{CO}_{2}(\mathrm{~g}) \leftrightarrows 2 \mathrm{CO}(\mathrm{g}) \quad \Delta \mathrm{H}_{298 \mathrm{~K}}=173 \mathrm{kJmol}^{-1}$ 
It is notable that the nitrogen content in the biochar produced with $\mathrm{K}_{2} \mathrm{CO}_{3}$ is lower than when using AC in MWP or when using CPS. The elevated ash contents for sample 13 and 14 are probably caused by the incomplete removal of $\mathrm{K}_{2} \mathrm{CO}_{3}$. 


\begin{tabular}{|c|c|c|c|c|c|c|c|c|c|c|c|c|c|}
\hline $\mathrm{N}^{\circ}$ & Sample & $\begin{array}{c}\text { Biochar } \\
\text { yield (\%) }\end{array}$ & $\mathrm{N}(\%)$ & C (\%) & $\mathrm{H}(\%)$ & $\mathrm{O}(\%)$ & Molar $\mathrm{H} / \mathrm{C}$ & Molar O/C & $\begin{array}{l}\text { Ash } \\
(\%)^{*}\end{array}$ & $\begin{array}{l}\text { MC } \\
(\%)^{*}\end{array}$ & $\operatorname{VM}(\%)^{*}$ & $\begin{array}{l}\mathrm{FC} \\
(\%)^{*}\end{array}$ & BS (\%) \\
\hline & Microwave pyrolysis & & & & & & & & & & & & \\
\hline 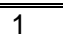 & MDF at $750 \mathrm{~W}$ & 44.3 & $2.49 \pm 0.10$ & $61.2 \pm 1.86$ & $5.28 \pm 0.16$ & $28.1 \pm 2.4$ & $1.03 \pm 0.03$ & $0.34 \pm 0.01$ & 2.9 & 1.0 & 51.9 & 44.6 & $46.8 \pm 3.1$ \\
\hline 2 & MDF at $1000 \mathrm{~W}$ & 44.5 & $2.54 \pm 0.09$ & $61.0 \pm 1.23$ & $5.27 \pm 0.09$ & $28.1 \pm 1.7$ & $1.03 \pm 0.02$ & $0.35 \pm 0.01$ & 3.0 & 0.8 & 48.3 & 47.8 & $52.9 \pm 2.7$ \\
\hline 3 & MDF at $1250 \mathrm{~W}$ & 43.8 & $2.33 \pm 0.09$ & $58.9 \pm 2.01$ & $5.21 \pm 0.13$ & $30.6 \pm 2.5$ & $1.06 \pm 0.03$ & $0.39 \pm 0.01$ & 2.9 & 0.8 & 43.5 & 53.3 & $58.7 \pm 5.4$ \\
\hline 4 & $\mathrm{MDF}+3 \% \mathrm{AC}-300 \mathrm{~W}$ & $50.0 \pm 0.9$ & $4.17 \pm 0.01$ & $59.5 \pm 0.43$ & $4.54 \pm 0.06$ & $27.5 \pm 0.9$ & $0.91 \pm 0.01$ & $0.35 \pm 0.01$ & 4.2 & 1.6 & 38.5 & 54.9 & $42.4 \pm 2.6$ \\
\hline 5 & $\mathrm{MDF}+5 \% \mathrm{AC}-300 \mathrm{~W}$ & $37.5 \pm 0.8$ & $4.49 \pm 0.06$ & $64.8 \pm 0.27$ & $3.73 \pm 0.05$ & $22.3 \pm 0.9$ & $0.69 \pm 0.01$ & $0.26 \pm 0.01$ & 4.6 & 1.5 & 24.8 & 68.4 & $49.9 \pm 4.2$ \\
\hline 6 & $\mathrm{MDF}+10 \% \mathrm{AC}-300 \mathrm{~W}$ & $34.9 \pm 3.2$ & $4.32 \pm 0.06$ & $62.8 \pm 0.88$ & $3.74 \pm 0.06$ & $24.2 \pm 1.5$ & $0.71 \pm 0.02$ & $0.29 \pm 0.01$ & 4.9 & 1.8 & 25.8 & 66.8 & $54.8 \pm 2.2$ \\
\hline 7 & $\mathrm{MDF}+3 \% \mathrm{AC}-400 \mathrm{~W}$ & $19.8 \pm 0.7$ & $3.72 \pm 0.03$ & $75.9 \pm 1.41$ & $1.25 \pm 0.01$ & $10.7 \pm 2.3$ & $0.20 \pm 0.01$ & $0.11 \pm 0.01$ & 8.4 & 1.5 & 2.7 & 85.8 & $97.4 \pm 0.9$ \\
\hline 8 & $\mathrm{MDF}+5 \% \mathrm{AC}-400 \mathrm{~W}$ & $21.8 \pm 1.3$ & $4.43 \pm 0.04$ & $74.2 \pm 0.99$ & $1.50 \pm 0.02$ & $12.0 \pm 1.9$ & $0.24 \pm 0.01$ & $0.12 \pm 0.01$ & 7.9 & 2.8 & 4.0 & 83.9 & $97.4 \pm 1.0$ \\
\hline 9 & $\mathrm{MDF}+10 \% \mathrm{AC}-400 \mathrm{~W}$ & $26.9 \pm 0.1$ & $4.88 \pm 0.02$ & $67.6 \pm 0.42$ & $2.59 \pm 0.11$ & $19.1 \pm 1.2$ & $0.46 \pm 0.04$ & $0.21 \pm 0.01$ & 5.8 & 3.0 & 13.9 & 76.1 & $60.0 \pm 1.1$ \\
\hline 10 & $\mathrm{MDF}+3 \% \mathrm{~K}_{2} \mathrm{CO}_{3}-300 \mathrm{~W}$ & $59.6 \pm 0.9$ & $3.62 \pm 0.11$ & $54.4 \pm 0.68$ & $5.09 \pm 0.04$ & $30.7 \pm 1.4$ & $1.12 \pm 0.01$ & $0.42 \pm 0.01$ & 6.2 & 2.7 & 48.1 & 41.8 & $49.5 \pm 1.0$ \\
\hline 11 & $\mathrm{MDF}+5 \% \mathrm{~K}_{2} \mathrm{CO}_{3}-300 \mathrm{~W}$ & $25.3 \pm 1.0$ & $3.52 \pm 0.09$ & $69.7 \pm 1.52$ & $2.06 \pm 0.05$ & $14.2 \pm 2.8$ & $0.35 \pm 0.02$ & $0.15 \pm 0.01$ & 10.5 & 2.5 & 11.2 & 71.2 & $95.3 \pm 1.1$ \\
\hline \multirow[t]{2}{*}{12} & $\mathrm{MDF}+10 \% \mathrm{~K}_{2} \mathrm{CO}_{3}-300 \mathrm{~W}$ & $27.5 \pm 1.0$ & $3.38 \pm 0.05$ & $71.5 \pm 0.57$ & $3.14 \pm 0.09$ & $11.8 \pm 1.7$ & $0.53 \pm 0.03$ & $0.12 \pm 0.01$ & 10.1 & 2.6 & 9.5 & 74.6 & $91.7 \pm 1.6$ \\
\hline & Conventional pyrolysis & & & & & & & & & & & & \\
\hline 13 & MDF at $350^{\circ} \mathrm{C}$ & $28.4 \pm 0.8$ & $4.92 \pm 0.11$ & $80.88 \pm 1.68$ & $3.40 \pm 0.09$ & $5.60 \pm 2.4$ & $0.50 \pm 0.03$ & $0.05 \pm 0.03$ & 5.2 & 1.8 & 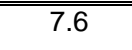 & 85.1 & $83.9 \pm 1.2$ \\
\hline \multirow[t]{2}{*}{14} & MDF at $450^{\circ} \mathrm{C}$ & $27.0 \pm 0.6$ & $4.54 \pm 0.10$ & $80.34 \pm 0.70$ & $2.91 \pm 0.06$ & $7.20 \pm 1.4$ & $0.43 \pm 0.02$ & $0.07 \pm 0.01$ & 5.0 & 1.5 & 4.1 & 88.6 & $92.1 \pm 0.8$ \\
\hline & Biomass & & & & & & & & & & & & \\
\hline 15 & MDF & 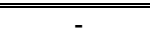 & $4.52 \pm 0.06$ & $46.79 \pm 0.31$ & $6.33 \pm 0.05$ & $41.0 \pm 0.5$ & $1.62 \pm 0.01$ & $0.66 \pm 0.01$ & 1.8 & 2.1 & 777.3 & 18.8 & 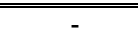 \\
\hline
\end{tabular}

Table 1: Biochar yield, proximate analysis, ultimate analysis and stability. MC stands for moisture content, VM is volatile matter, FC is fixed carbon and BS is biochar stability. *error on proximate analysis is $10 \%$. 


\section{FTIR analysis}

In this study, FT-IR is not only used to unravel which functional groups are present in the biochar but also as a screening tool to select the most interesting samples to be analyzed by ${ }^{13} \mathrm{C}$ solid-state NMR spectroscopy. Both techniques are complementary and yield the information needed to select suitable applications for the biochar.

The IR spectrum of MDF biomass (figure 4A) shows typical bands referring to cellulose, hemicellulose and lignin. A detailed wavenumber assignment for MDF can be found in ref [46]. ATR FT-IR spectra of biochars obtained by CPS at $350^{\circ} \mathrm{C}$ and $450^{\circ} \mathrm{C}$ show a similar pattern (figure 4B). A broad peak between 3600 and $3000 \mathrm{~cm}^{-1}$ in its ATRFTIR spectra can be assigned to a multitude of $\mathrm{OH}$ - and $\mathrm{NH}$-stretching frequencies in phenolic and $\mathrm{H}$-bonded hydroxyl groups $[40,41,42]$. This broad band is more intense at $350^{\circ} \mathrm{C}$, suggesting more degradation at $450{ }^{\circ} \mathrm{C}$. The presence of the bands between 2850 and $2960 \mathrm{~cm}^{-1}$ can be assigned to $\mathrm{C}-\mathrm{H}$ symmetric and asymmetric stretching of residual $\mathrm{CH}_{\mathrm{x}}$ groups $[40,42,43]$. The shoulder around $1690 \mathrm{~cm}^{-1}$ can be assigned to $\mathrm{C}=\mathrm{O}$ stretching as found in aromatic aldehydes, ketones and carboxylic acids. The broad band around $1588 \mathrm{~cm}^{-1}$ can be attributed to the $\mathrm{C}=\mathrm{C}$ stretching of aromatic moieties and is considered as a measure for aromatisation during the carbonisation process. The band at $1434 \mathrm{~cm}^{-1}$ is assigned to $\mathrm{C}=\mathrm{C}$ stretching in aromatic ring structures and $\mathrm{C}-\mathrm{H}$ deformations and is less resolved in the IR spectrum of the biochar obtained at $450^{\circ} \mathrm{C}$ demonstrating the decrease of $\mathrm{C}-\mathrm{H}$ bonds in favour of aromatisation. The broad bands between 1100-1300 $\mathrm{cm}^{-1}$ can be assigned to C-N and C-O functionalities. Peaks at 874,813 and $756 \mathrm{~cm}^{-1}$ are characteristic for aromatic C-H out-of-plane bending and are more dominant present in the IR spectrum of the biochar produced at $450^{\circ} \mathrm{C}$ illustrating a higher degree of aromatisation.

FT-IR spectra from biochars produced at $300 \mathrm{~W}$ with different quantities of $\mathrm{AC}$ illustrate the increase of carbonisation as a result of increased MW absorber (Figure 4C). A decreased intensity of O-H stretching vibrations (3600-3000 $\left.\mathrm{cm}^{-1}\right)$ coinciding with a decrease in the C-H stretch $\left(2960-2850 \mathrm{~cm}^{-1}\right)$, carbonyl stretch $\left(1715-1690 \mathrm{~cm}^{-1}\right)$ and and intense C-O stretch in C-O-C functionalities $\left(1200-1000 \mathrm{~cm}^{-1}\right)$ is observed with an increased amount of MW absorber. In contrast the contribution of $\mathrm{C}=\mathrm{C}$ stretch (aromatic ring structures, $1580-1500 \mathrm{~cm}^{-1}$ and $1480-1400 \mathrm{~cm}^{-}$ 1) to the overall IR spectrum is more pronounce for a $10 \%$ addition of AC. This observation is in line with lower volatile matter content and an increased fixed carbon content (table 1). Weak signals of aromatic ring structures were observed between the wavenumbers $900-660 \mathrm{~cm}^{-1}$. When 3 and $5 \%$ of AC was added, absorption bands of $\mathrm{C}=\mathrm{O}$ (carbonyl) around $1715-1690 \mathrm{~cm}^{-1}$ were observed, present as a shoulder, but almost not detected in case of $10 \%$ addition of $\mathrm{AC}$. When adding more $\mathrm{AC}$, the reduction of aliphatic $\mathrm{C}-\mathrm{H}$ stretch is in accordance with a decreased $H$ content (table 1).

FT-IR spectra from biochars produced at $400 \mathrm{~W}$ with different quantities of AC (Figure 4D) can be differentiated from the spectra obtained for the biochars produced at $300 \mathrm{~W}$. In this case a further decrease in $\mathrm{O}-\mathrm{H}$ and $\mathrm{C}-\mathrm{H}$ functionalities is found. The presence of carbonyl groups is only observed for a $10 \% \mathrm{AC}$ addition, indicating less aromatic structures. The broad peak from 3600 to $3100 \mathrm{~cm}^{-1}$ is assigned to multiple $\mathrm{OH}$ - and NH-stretching in the phenolic and aliphatic structures of the remaining cellulose, hemicellulose and lignin. The peaks at 1575 and 1425 $\mathrm{cm}^{-1}$ are assigned to $\mathrm{C}-\mathrm{H}$ and $\mathrm{C}-\mathrm{N}$ functionalities and their intensities increase when $10 \%$ of AC added, indicating a lower degree of decomposition and aromatization, confirmed by biochar yield, ultimate and proximate analysis and biochar stability. The peak at $875 \mathrm{~cm}^{-1}$ represents the out-of-plane deformation of aromatic C-H bonds and can be assigned to aromatic $\mathrm{C}=\mathrm{C}$ or $\mathrm{C}=\mathrm{N}$ bonds and $\mathrm{C}-\mathrm{H}$ bonds [51].

The FT-IR spectrum for biochar obtained from MWP with $3 \% \mathrm{~K}_{2} \mathrm{CO}_{3}$ (Figure $4 \mathrm{E}$ ) showed minor differences with the FTIR features for the original lignocellulosic material indicating that lignin, cellulose and hemicellulose were not completely carbonized as confirmed by biochar yield, ultimate analysis and biochar stability. Comparing IR spectra of biochars with addition of 5 and $10 \% \mathrm{AC}$, almost no differences were observed in the overall IR pattern of both biochars. A significant decrease in the aliphatic $\mathrm{C}-\mathrm{H}$ stretch at $3000-2860 \mathrm{~cm}^{-1}$ coincide with the appearance of a 
prominent broad signal around $1650-1550 \mathrm{~cm}^{-1}$ of merged aromatic ring systems and the appearance of the signal of the aromatic $\mathrm{C}-\mathrm{H}$ bonds at $875 \mathrm{~cm}^{-1}$ were observed when comparing to the IR spectra of biochar with $3 \%$ of $\mathrm{K}_{2} \mathrm{CO}_{3}$. When comparing these spectra with the spectra from biochar produced at $300 \mathrm{~W}$ with $\mathrm{AC}$ as MWA, it becomes clear that more aromatization already occurred for the same amount of $\mathrm{K}_{2} \mathrm{CO}_{3}$ compared to $\mathrm{AC}$ as MWA. Infrared spectra of the samples produced without MWA at $750 \mathrm{~W}, 1000 \mathrm{~W}$ and $1250 \mathrm{~W}$ (Figure 4F) are very similar and resemble the spectra of biochar produced at $300 \mathrm{~W}$ with $3 \%$ and $5 \%$ of $A C$ (figure $4 C$ ), revealing that limited pyrolysis occurred as reflected by ultimate and proximate analysis and biochar stability (table 1).
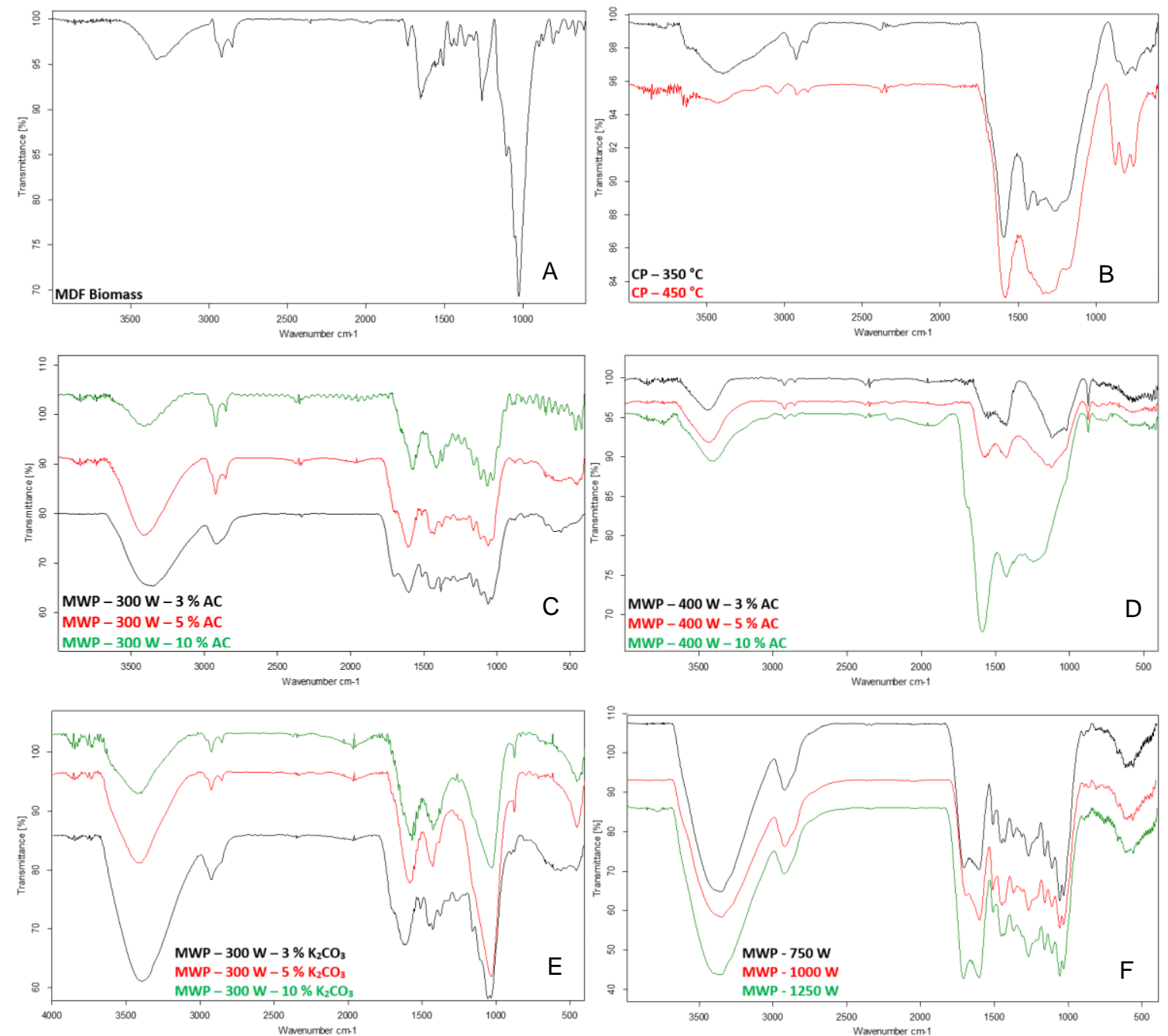

Figure 4: FTIR spectra of different biochars; A: spectrum of the MDF biomass; B: spectra for biochar produced by CPS at $350{ }^{\circ} \mathrm{C}$ and $450{ }^{\circ} \mathrm{C}$; C: spectra for biochars produced at $300 \mathrm{~W}$ with $3 \%, 5 \%$ and $10 \%$ of AC; D: spectra for biochar produced at $400 \mathrm{~W}$ with $3 \%, 5 \%$ and $10 \%$ of AC; E: spectra for biochar produced at $300 \mathrm{~W}$ with $3 \%$, $5 \%$ and $10 \%$ of $\mathrm{K}_{2} \mathrm{CO}_{3} ; \mathrm{F}$ : spectra for biochars produced at $750 \mathrm{~W}, 1000 \mathrm{~W}$ and $1250 \mathrm{~W}$ without MWA.

\section{SEM analysis}

Comparison of surface morphology confirms that substantial changes occurred due to decomposition of the MDF. When comparing the SEM images of biochar that has been the result of pyrolysis with a higher conversion degree (figure $5 \mathrm{~A}: 300 \mathrm{~W}$ with $5 \% \mathrm{~K}_{2} \mathrm{CO}_{3}$ and figure $5 \mathrm{~B}$ : $400 \mathrm{~W}$ with $3 \% \mathrm{AC}$ respectively) with biochar that has been the result of pyrolysis with a lower conversion degree (figure $6 \mathrm{C}$, biochar produced at $300 \mathrm{~W}$ with $10 \% \mathrm{AC}$ ), an indication for a more open surface structure was observed. The surface of the biochar with a higher yield of $34.9 \%$ (figure 5C) shows only minor differences with the surface of the initial material (figure 5E). If biochar produced with MWP is compared to biochar produced with CPS at comparable temperatures (figure 5D), it is clear that MWP yields a biochar that has a more open surface structure. The formation of this type of morphology is highlighted with 
red circles in figure 5 and is attributed to the release of gasses from the inside of the particles to the outside through the surface. This ensures the formation of a more open surface structure [29,33].

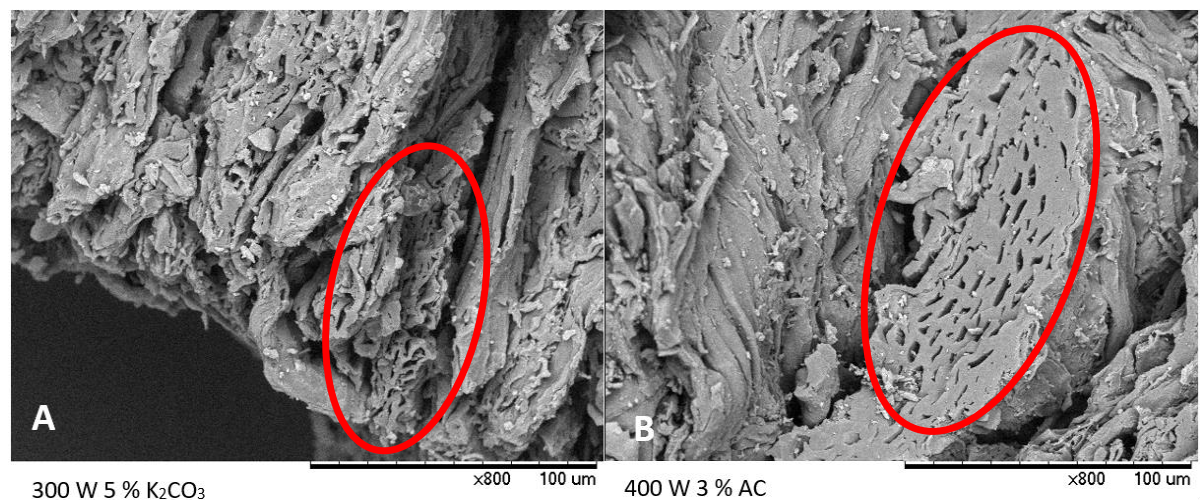

\begin{abstract}
$300 \mathrm{~W} 5 \% \mathrm{~K}_{2} \mathrm{CO}_{3}$
\end{abstract}

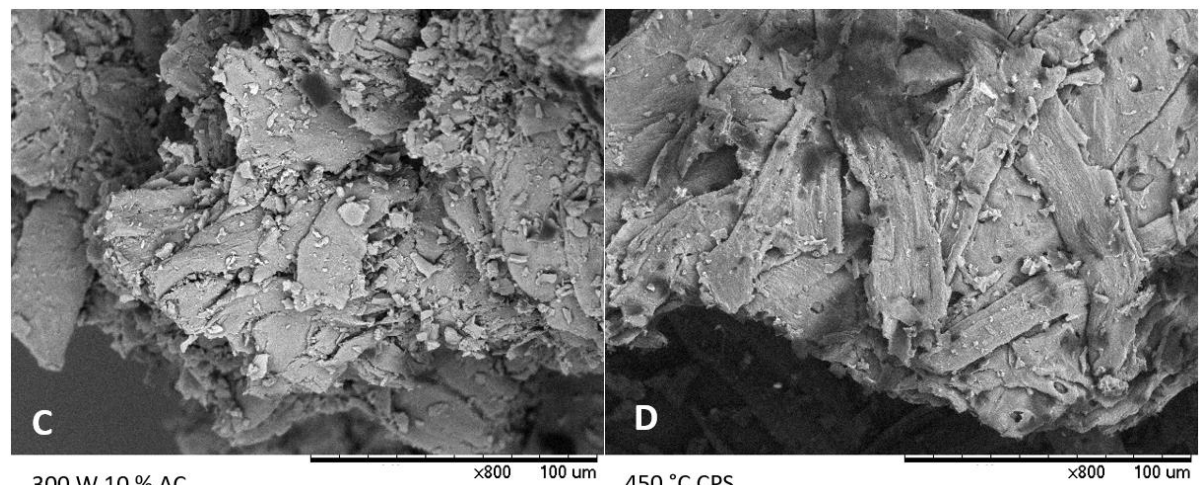

300 W $10 \%$ AC

$450^{\circ} \mathrm{C}$ CPS

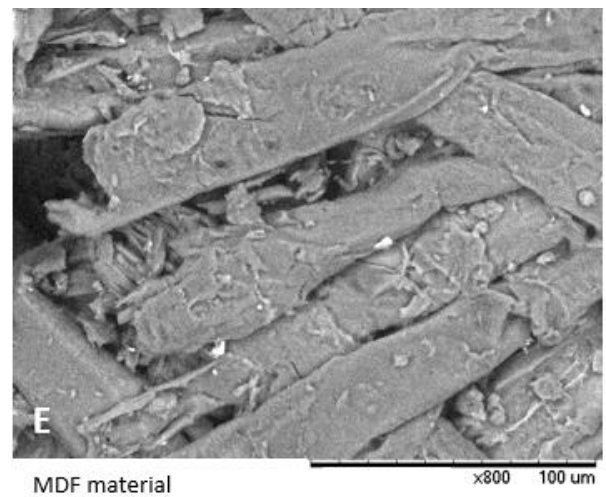

Figure 5: SEM images of different biochars: A: produced at $300 \mathrm{~W}$ with $10 \% \mathrm{~K}_{2} \mathrm{CO}_{3}$, B: produced at $400 \mathrm{~W}$ with 3 $\% \mathrm{AC}, \mathrm{C}$ : produced at $300 \mathrm{~W}$ with $10 \% \mathrm{AC}$, D: produced through $\mathrm{CPS}$ at $450{ }^{\circ} \mathrm{C}$ and $\mathrm{E}$ : an image of the MDF material. 


\section{7. ${ }^{13} \mathrm{C}$ solid-state CP/MAS NMR spectroscopy}

In contrast to FTIR spectra where differences between complete and partially pyrolyzed samples are often difficult to interpret because of overlapping signals, ${ }^{13} \mathrm{C}$ solid-state NMR spectra is more convenient as the NMR scale offers more differentiation between aliphatic $\mathrm{C}-\mathrm{O}$ and $\mathrm{C}-\mathrm{N}$ functionalities, carbonyl functional groups and aromatic carbon signals. In turn, more chemically detailed and quantitative information can be deduced [48,49], which allows the monitoring of the pyrolytic conversion of the lignocellulosic material into the biochar. Moreover, this kind of information is useful in view of interpreting the influence of the process parameters and other characteristics of the biochar which are important for long term applications, e.g. long-term stability. On the basis of the outcome of the other analyses techniques used, only the extreme samples were selected and analysed in this study since all necessary conclusions can already be drawn from these samples. Although the signal intensity in ${ }^{13} \mathrm{C}-\mathrm{CP} / \mathrm{MAS}$ solid-state NMR spectra is semi-quantitative, similar species having similar chemical functionalities can be compared relatively to each other and good estimates of the amount of these functional groups can be made on the basis of the peak areas (integration values). The major signal assignments can be found in table 2 and in literature [54].

\begin{tabular}{|l|l|}
\hline \multicolumn{2}{|c|}{ Carbon signal (ppm) } \\
\hline Carbonyl & $225-185$ \\
$\mathrm{C}=\mathrm{O}$ & $185-165$ \\
$\mathrm{O}=\mathrm{C}-\mathrm{O}$ & \\
Aromatic & $165-145$ \\
$\mathrm{C}-\mathrm{OH}$ and C-OR & $145-110$ \\
$\mathrm{C}$ (non-protonated) and CH & \\
Aliphatic & $110-50$ \\
$\mathrm{H}-\mathrm{C}-\mathrm{O}$ & $50-25$ \\
$\mathrm{H}-\mathrm{C}-\mathrm{N}$ & $50-15$ \\
$\mathrm{CH}, \mathrm{CH}$ & $25-6$ \\
$\mathrm{CH}$ & \\
\hline
\end{tabular}

Table 2: Major assignments of signals in ${ }^{13} \mathrm{C}$ solid state NMR spectra

\begin{tabular}{|c|c|c|c|c|}
\hline Sample & Carbonyl C (\%) & Aromatic C (\%) & Aliphatic C (\%) & Stability (\%) \\
\hline \multicolumn{5}{|l|}{ Microwave pyrolysis } \\
\hline$\overline{\mathrm{MDF}}+3 \% \mathrm{AC}$ at $300 \mathrm{~W}$ (MWP) & 7.1 & 51.7 & 41.2 & 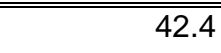 \\
\hline $\mathrm{MDF}+10 \% \mathrm{AC}$ at $300 \mathrm{~W}$ (MWP) & 6.0 & 62.4 & 31.6 & 54.8 \\
\hline $\mathrm{MDF}+3 \% \mathrm{AC}$ at $400 \mathrm{~W}$ (MWP) & N.D. & 100 & N.D. & 97.4 \\
\hline $\mathrm{MDF}+10 \% \mathrm{AC}$ at $400 \mathrm{~W}$ (MWP) & 8.1 & 73.1 & 18.8 & 60.0 \\
\hline $\mathrm{MDF}+3 \% \mathrm{~K}_{2} \mathrm{CO}_{3}$ at $300 \mathrm{~W}(\mathrm{MWP})$ & 4.4 & 35.6 & 60.0 & 49.5 \\
\hline $\mathrm{MDF}+10 \% \mathrm{~K}_{2} \mathrm{CO}_{3}$ at $300 \mathrm{~W}$ (MWP) & 7.3 & 86.5 & 6.2 & 91.7 \\
\hline MDF at $750 \mathrm{~W}$ (MWP) & 6.4 & 45.0 & 48.5 & 46.8 \\
\hline MDF at $1250 \mathrm{~W}$ (MWP) & 6.6 & 48.2 & 45.2 & 58.8 \\
\hline \multicolumn{5}{|l|}{ Conventional pyrolysis } \\
\hline MDF at $350^{\circ} \mathrm{C}(\mathrm{CPS})$ & 5.0 & 75.6 & $\overline{19.4}$ & 83.9 \\
\hline MDF at $450^{\circ} \mathrm{C}(\mathrm{CPS})$ & 2.3 & 86.8 & 11.0 & 92.1 \\
\hline
\end{tabular}

Table 3: Aromatic $\mathrm{C}$ and stability of the samples measured by ${ }^{13} \mathrm{C}$ solid state NMR. N.D stands for not detected. 
Biochar produced from MDF at $300 \mathrm{~W}$ with 3 and $10 \% \mathrm{AC}$ (Figure $6 \mathrm{~A}$ ) contains several distinct peaks in the 50 90 ppm range, which can be mainly attributed to $\mathrm{C}-\mathrm{O}$ moieties and nitro groups. The signal from 90 to $110 \mathrm{ppm}$ can be attributed to $\mathrm{O}-\mathrm{C}-\mathrm{O}$ functionalities. $\mathrm{Csp}^{2}$ in aromatic rings and unsaturated $\mathrm{C}=\mathrm{C}$ bonds can be found in the spectral range 115-165 ppm. Carboxylic acids $(\mathrm{COOH})$, esters (COOR) and amides (CONR 2$)$ can be found in the 165-185 ppm range, while aldehydes and ketones are situated more downfield above 185 ppm. Biochar produced with $10 \% \mathrm{AC}$ at $300 \mathrm{~W}$ contains less resonance signals of hydrocarbons $\left(\mathrm{CH}_{3}, \mathrm{CH}_{2}\right.$ and $\left.\mathrm{CH}\right)$ in the 6-50 ppm range. Sharp signals at 106, 88, 85 and 65 ppm in the NMR spectrum for the biochar at 300W can be assigned to residual cellulose indicating an incomplete thermal conversion [55]. The large signal around $75 \mathrm{ppm}$ is indicative for $\mathrm{COH} / \mathrm{COR}$ moieties. The signal between 145-165 ppm could be related to aromatic $\mathrm{COH} / \mathrm{COR}$ functionalities. The normalized integration values show that increasing the AC content to $10 \%$ results in a decrease of the fractions of aliphatic hydrocarbons (6-50 ppm) and oxygenated aliphatics (50-90 ppm) carbons in favour of an increase of the aromatic carbon signals (100-165 ppm). These observations are in agreement with the outcome of FT-IR spectra of corresponding biochars (Figure 6A) and was explained as the result of enhanced aromaticity and because of enhanced temperature when more $\mathrm{AC}$ was added. As can be seen in table 3 , the total aromatic $\mathrm{C}$ increases, while carbonyl $\mathrm{C}$ and aliphatic $\mathrm{C}$ decreases upon going from $3 \%$ to $10 \% \mathrm{AC}$.

When a microwave power of $400 \mathrm{~W}$ was applied and AC was added as MWA at 3 and $10 \%$ (Figure 6B), the NMR spectra are dominated by the aromatic peak centred at around $130 \mathrm{ppm}$. These results clearly demonstrate a link between structural characteristics of aromaticity and the applied microwave power. When higher microwave power is applied combined with addition of $\mathrm{AC}$ as MW absorber, an increased reaction temperature and enhanced aromaticity of the biochar is achieved. Higher aromaticity at higher pyrolysis temperatures was already suggested by McBeath et al. [56]. Main difference between both spectra is the decrease of the signal of aromatic $\mathrm{COH} / \mathrm{COR}$ moieties within the 110-165 ppm range when using $10 \% \mathrm{AC}$ and increased carbonyl and aliphatic functionalities (table 3). Biochar stability and molar $\mathrm{H} / \mathrm{C}$ ratio (table 1 ) of the char produced with $10 \% \mathrm{AC}$ are respectively significantly lower and higher than for the char produced with $3 \% \mathrm{AC}$. The same conclusion can be drawn from the NMR results, as aromatic $C$ increases and carbonyl $C$ and aliphatic $C$ deceases when only $3 \%$ of $A C$ is added.

When applying $300 \mathrm{~W}$ with $3 \% \mathrm{~K}_{2} \mathrm{CO}_{3}$ (Figure $6 \mathrm{C}$ ), a similar ${ }^{13} \mathrm{C}$ solid-state NMR spectrum is found as for the biochar produced at $300 \mathrm{~W}$ with $3 \% \mathrm{AC}$, but with a significant lower aromatic fraction (table 3) and an important fraction of aliphatic C-O, C-N functionalities and aliphatic carbons. This is also confirmed by ultimate analysis, proximate analysis and biochar stability (table 1 ). When $10 \%$ of $\mathrm{K}_{2} \mathrm{CO}_{3}$ was added to the MDF, the spectrum was dominated by the aromatic signal around $130 \mathrm{ppm}$. Almost no other functionalities were detected, apart from a weak signal around 160 ppm possibly corresponding with aromatic $\mathrm{COH} / \mathrm{COR}$ functionalities.

Biochar produced without the use of MWA at $750 \mathrm{~W}$ and $1250 \mathrm{~W}$ (Figure 6D) displays the same spectrum pattern for biochar produced at $300 \mathrm{~W}$ with $3 \%$ of $\mathrm{AC}$, but with slightly different relative fractions (table 3 ). Since all these biochar's have a similar $\mathrm{H} / \mathrm{C}$ ratio and the infrared spectra are resembling, this is an expected result. The aromatic signal around $130 \mathrm{ppm}$ is somewhat more intense in the spectrum of the biochar produced at $1250 \mathrm{~W}$, explaining the relative higher biochar stability and higher aromatic $\mathrm{C}$ content in comparison to $750 \mathrm{~W}$. A higher microwave power without addition of a MWA therefore leads to a higher degree of aromaticity.

Apart from the aromatic signal around $130 \mathrm{ppm}$, biochar produced at $350^{\circ} \mathrm{C}$ through $\mathrm{CPS}$ (figure $6 \mathrm{E}$ ) shows small resonance signals within 10-40 ppm and 70-80 ppm, indicating that this biochar still has some hydrocarbons and $\mathrm{C}-\mathrm{N}$ and $\mathrm{C}-\mathrm{O}$ moieties. Biochar produced at $450^{\circ} \mathrm{C}$ (figure $6 \mathrm{E}$ ) only shows the aromatic signal as major component with minor amounts of aliphatics. Total aromatic $\mathrm{C}$ is therefore higher for biochar produced at $450{ }^{\circ} \mathrm{C}$ (table 3 ). Biochar produced at higher temperatures therefore has a higher degree of aromaticity $[31,56]$.

It can be seen that MWP with the addition of MWA can generate biochar with a higher degree of aromaticity at lower temperatures than CPS. Biochar produced from MDF with a MWP of $400 \mathrm{~W}$ and $3 \%$ of AC as well as biochar 
produced with a MWP at $300 \mathrm{~W}$ and $10 \%$ of $\mathrm{K}_{2} \mathrm{CO}_{3}$ both show a higher $\mathrm{H} / \mathrm{C}$ ratio, a comparable or higher biochar stability and higher aromaticity as compared to biochars produced by $\mathrm{CPS}$ at $350{ }^{\circ} \mathrm{C}$ or $450{ }^{\circ} \mathrm{C}$.
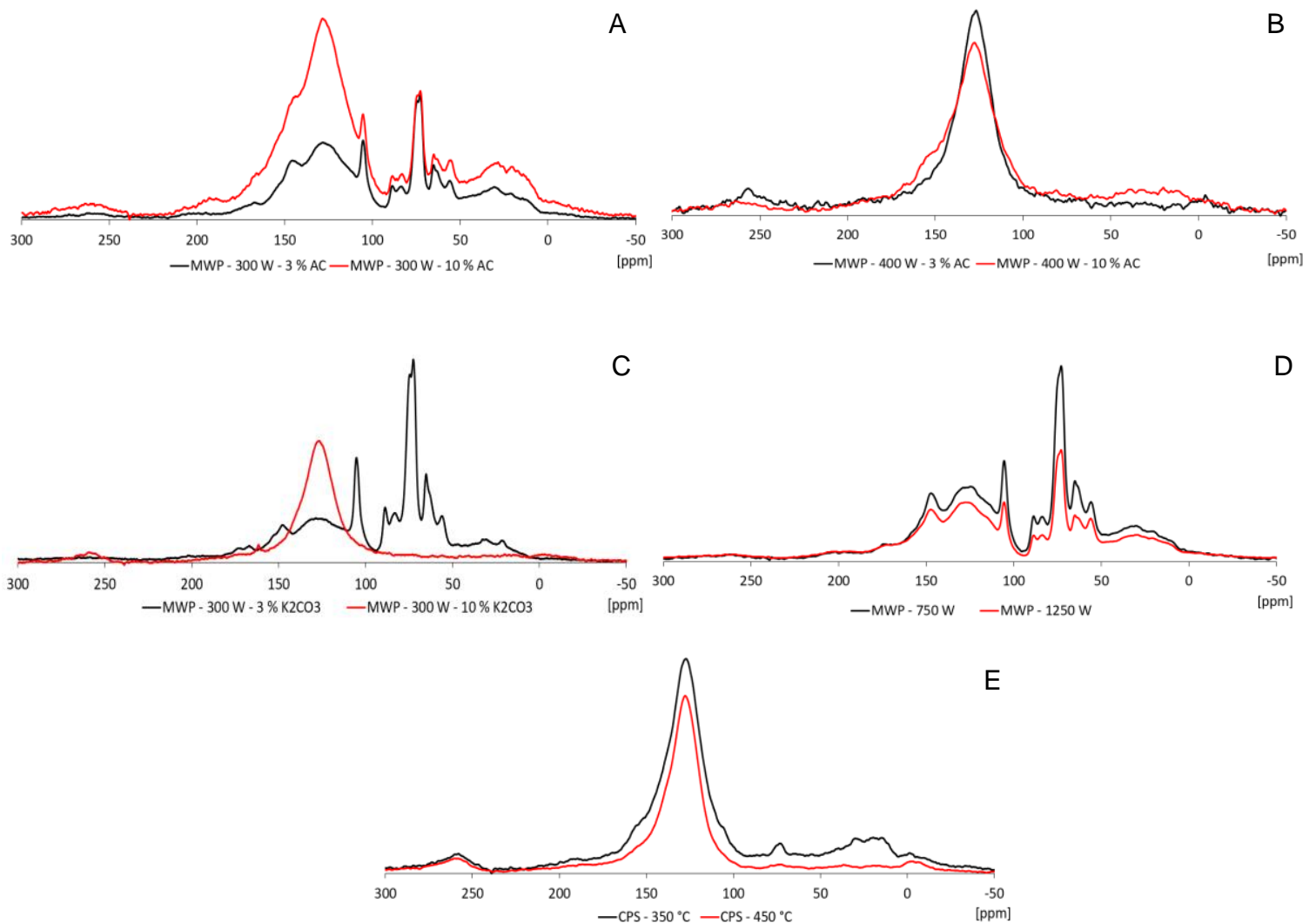

Figure 6: Solid-state 13C CP NMR spectra of different biochars; A: the spectrum for biochar produced at $300 \mathrm{~W}$ with $3 \%$ and $10 \%$ of AC; B: spectrum for biochar produced at $400 \mathrm{~W}$ with $3 \%$ and $10 \%$ of AC; C: spectrum for biochar produced at $300 \mathrm{~W}$ with $3 \%$ and $10 \%$ of $\mathrm{K}_{2} \mathrm{CO}_{3}$; D: spectrum of biochar produced at $750 \mathrm{~W}$ and $1250 \mathrm{~W}$ without MWA; E: spectrum for biochar produced through CPS at $350^{\circ} \mathrm{C}$ and $450{ }^{\circ} \mathrm{C}$. The signals at $-5 \mathrm{ppm}$ and 265 $\mathrm{ppm}$ are spinning side bands of the main aromatic signal around $130 \mathrm{ppm}$.

\section{Correlation between the results and impact of the research}

When the results of table 1 are presented graphically, correlations between the results are found (figures 7 A-F). The graphs for fixed $C$ vs. volatile matter (figure 7A) shows a linear correlation for all biochar samples. It is notable that the samples produced with $\mathrm{K}_{2} \mathrm{CO}_{3}$ as a MWA show lower amounts of fixed $\mathrm{C}$ for the same amount of volatile matter that is left in the materials. This is due to reaction (6). Biochar produced through CPS and MWP at $400 \mathrm{~W}$ with $A C$ have the highest amount of fixed $C$ and the lowest amount of volatile matter. Next to fixed $C$, biochar stability is also linearly correlated with volatile matter as can be seen in figure 7B. All biochars that were not completely carbonized and produced with the use of a MWA (sample 4,5,6 and 9) show a considerably lower stability, which is probably due to the high amount of oxygen groups that are still left in the biochar and are easily broken down by $\mathrm{H}_{2} \mathrm{O}_{2}$ in the stability test.

When biochar stability is plotted vs. $\mathrm{O} / \mathrm{C}$ ratio and $\mathrm{H} / \mathrm{C}$ ratio (figure $7 \mathrm{C}$ and $7 \mathrm{D}$ ), two relatively similar graphics with strong correlations are found as also described by Crombie et al. [57]. This indicates that the less $\mathrm{O}$ and $\mathrm{H}$ are still left in the biochar, the more stable the biochar becomes. A low $\mathrm{H} / \mathrm{C}$ ratio indicates a high degree of aromaticity and a high resistance against chemical and bacteriological decomposition, while a decreasing $\mathrm{O} / \mathrm{C}$ ratio indicates the evolution of the carbonization process. $\mathrm{H} / \mathrm{C}$ and $\mathrm{O} / \mathrm{C}$ ratios decrease with increasing pyrolysis temperature [58]. The only clear difference between the two graphs is that even though the biochars produced through CPS have the lowest $\mathrm{O} / \mathrm{C}$ ratio, indicating the pyrolysis process is developed the furthest, they do not have the lowest $\mathrm{H} / \mathrm{C}$ ratio. 
This indicates a lower degree of aromaticity in the biochars produced at comparable temperatures through CPS than those produced by MWP. A lower O/C ratio does however indicate that biochar produced through CPS could serve as a better carbon sink [22].

It can be seen in the Van Krevelen diagram (figure 7E) that the $\mathrm{O} / \mathrm{C}$ vs. $\mathrm{H} / \mathrm{C}$ ratio for all the biochars produced by MWP show a linear correlation (except for sample 12, which is due to a lower degree of carbonization and less aromatization. This indicates again that optimal pyrolysis conditions are reached when $5 \%$ of $\mathrm{K}_{2} \mathrm{CO}_{3}$ is added). The biochars produced through CPS show a higher $\mathrm{H} / \mathrm{C}$ ratio for the same O/C ratio than the biochars produced through MWP, again indicating a lower degree of aromatisation.

From figure 7F it becomes clear that the biochar stability test can serve as an alternative for ${ }^{13} \mathrm{C}$ solid-state CP/MAS NMR spectroscopy, as the results of both techniques are very similar to each other. Biochar stability test can therefore be applied as a cheap and fast technique to form an accurate conclusion about the application possibilities of a certain biochar. For detailed information about the composition of the material, ${ }^{13} \mathrm{C}$ solid-state NMR is, however, necessary.

This study demonstrates that both CPS and MWP are viable options for transforming MDF into value added biochar. Low power MWP with activated carbon as a MWA or CPS at moderate temperatures (350 to $450{ }^{\circ} \mathrm{C}$ ) will result in a biochar that is less aromatic and therefore less stable. Such biochars will be effective as a soil amendment. When considering a biochar that has to have an open surface structure, combined with a high degree of aromaticity and stability, MWP at higher microwave powers or a more effective MWA like $\mathrm{K}_{2} \mathrm{CO}_{3}$ should be used. All of these characteristics are achieved at lower temperature with MWP than with CPS and are favourable if the biochar is used for adsorption purposes or as a precursor for activated carbon. 

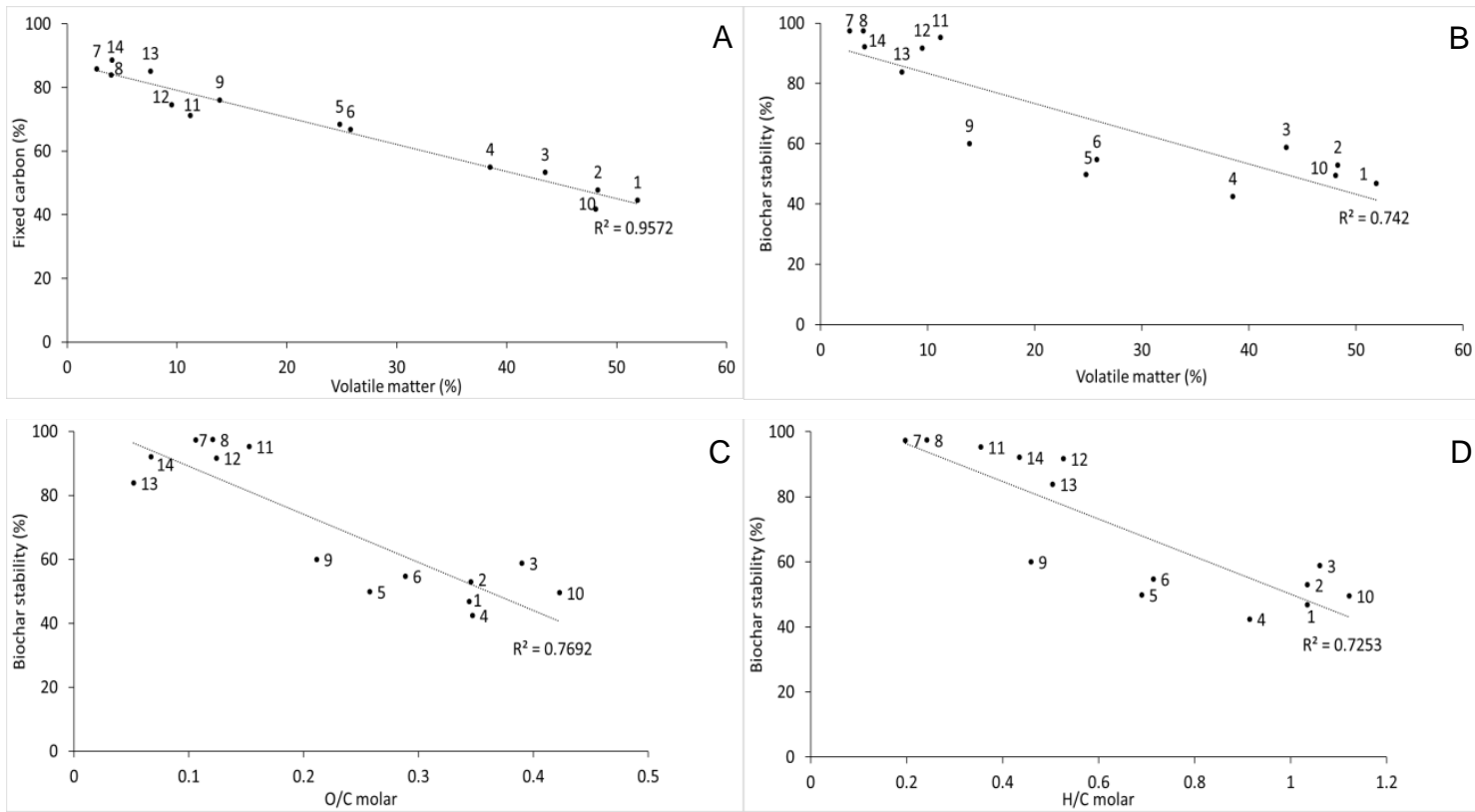

C
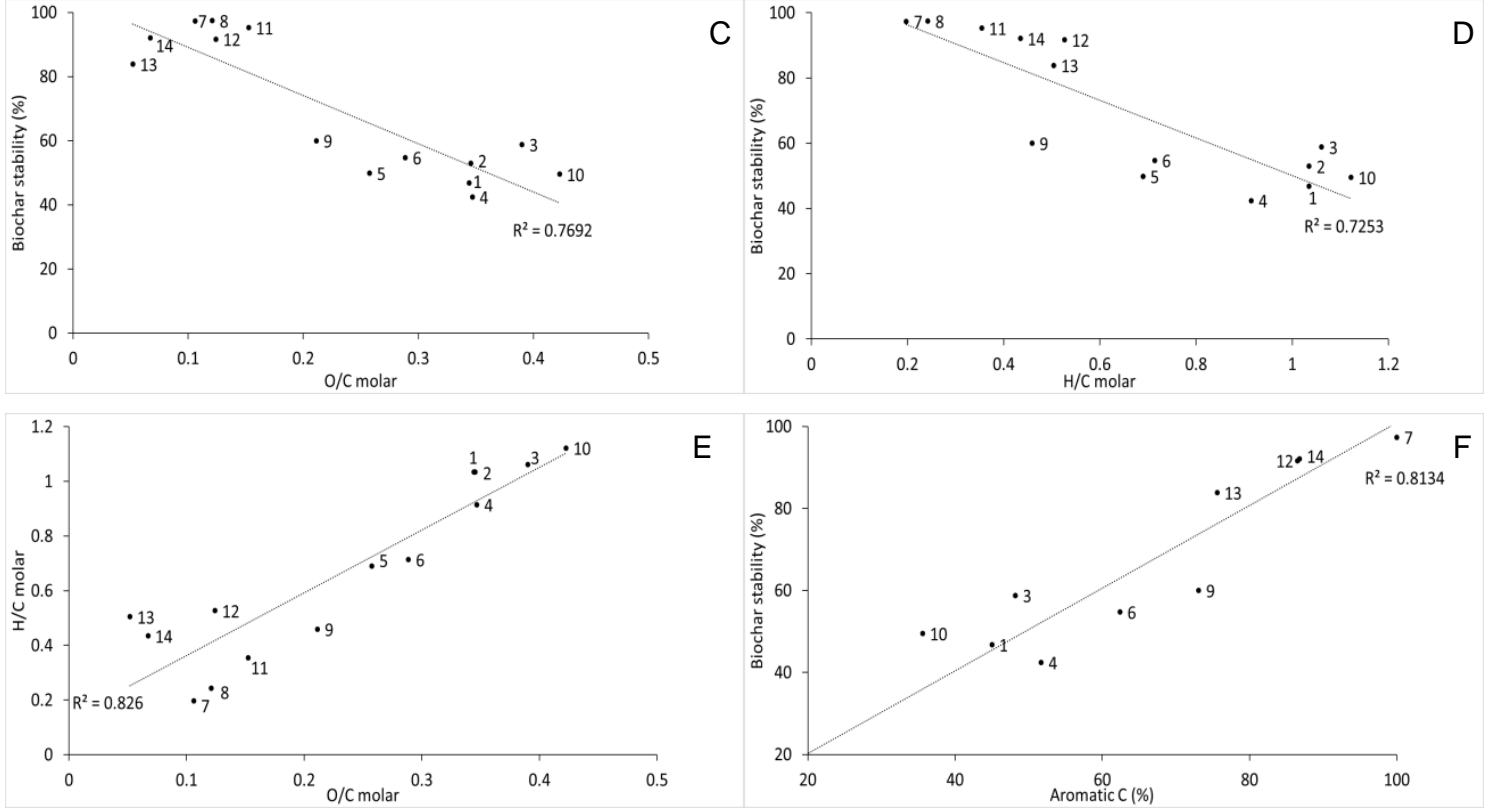

Figure 7: Graphic representation of the results of the 14 different samples described in table 1:, A: fixed $C$ vs. volatile matter, B: biochar stability vs. volatile mater, C: biochar stability vs. O/C molar, D: biochar stability vs. H/C molar, E: Van Krevelen diagram and F: biochar stability vs. aromatic C. Sample numbers refer to table 1. 


\section{Conclusion}

The chemical properties of the different biochars obtained through two different pyrolysis techniques, CPS and MWP, are evaluated comparing biochar yield, ultimate analysis, proximate analysis, biochar stability test, FTIR spectroscopy and solid-state ${ }^{13} \mathrm{C}$ CP/MAS NMR spectroscopy.

When no MWA is added to the MDF sample in MWP, a higher power causes a more stable material. The addition of $A C$ as a MWA at a low microwave power of $300 \mathrm{~W}$ is beneficial for the pyrolysis process. Increasing amounts of $A C$ leads to a higher degree of carbonization due to the localized indirect heating caused by the AC. At a higher microwave power of $400 \mathrm{~W}$, increasing amounts of $A C$ caused a decreasing biochar yield, biochar stability, fixed carbon content, aromatic carbon content and $\mathrm{H} / \mathrm{C}$ ratio. Optimal pyrolysis conditions are already reached when only $3 \%$ of $A C$ is added, which is beneficial for economic reasons. When adding $\mathrm{K}_{2} \mathrm{CO}_{3}$ instead of $\mathrm{AC}$ as a MWA in MWP at the same microwave power, It can be concluded that this yields biochar that has been more carbonized and aromatized when at least $5 \%$ of $\mathrm{K}_{2} \mathrm{CO}_{3}$ is added. This is caused by the strong catalytic effect of $\mathrm{K}_{2} \mathrm{CO}_{3}$ at high pyrolysis temperatures. Optimal pyrolysis conditions are reached when $5 \%$ of $\mathrm{K}_{2} \mathrm{CO}_{3}$ is added.

Both CPS and MWP are viable options for transforming MDF into a value-added biochar at the end of its lifetime although biochar from MWP is generally more aromatic at lower pyrolysis temperatures. When considering the possible applications of a certain biochar, the stability test provides valuable information while still being cheap and fast.

\section{Acknowledgements}

Koen Van Vinckenroye for support with the ${ }^{13} \mathrm{C}$ solid state NMR measurements

Elsy Thijssen and Martine Vanhamel for FTIR measurements

This work was supported by Agentschap Innoveren en Ondernemen (VLAIO) [BM20160604]; European Institute of Technology (EIT); and Research Foundation Flanders (postdoctoral fellowship D. Vandamme [FWO - 12D8914N]).

\section{Bibliography}

[1] R. Garcia, F. Freire, Carbon footprint of particleboard: a comparison between ISO/TS 14067, GHG Protocol, PAS 2050 and Climate Declaration, J. Clean. Prod. 66 (2014) 199-209. http://doi.org/10.1016/j.jclepro.2013.11.073.

[2] Food and Agriculture Organistation of the United Nations, Food and agriculture data. http://www.fao.org/faostat/en/, 2017 (accessed August 30, 2018).

[3] S. Reza, F. Teymour, V. Ehsan, Thin particleboard quality : effect of particle size on the properties of the panel, J. Indian Acad. Wood Sci. 13 (2016) 38-43. http://doi.org/10.1007/s13196-016-0163-9.

[4] P. Girods, A. Dufour, Y. Rogaume, C. Rogaume, Pyrolysis of wood waste containing urea-formaldehyde and melamine-formaldehyde resins, J. Anal. Appl. Pyrolysis. $81 \quad$ (2008) $113-120$. http://doi.org/10.1016/j.jaap.2007.09.007.

[5] P. Girods, A. Dufour, Y. Rogaume, C. Rogaume, A. Zoulalian, Thermal removal of nitrogen species from wood waste containing urea formaldehyde and melamine formaldehyde resins, J. Hazard. Mater. 159 (2008) $210-221$. http://doi.org/10.1016/j.jhazmat.2008.02.003.

[6] P. Girods, A. Dufour, Y. Rogaume, C. Rogaume, Journal of Analytical and Applied Pyrolysis Comparison of gasification and pyrolysis of thermal pre-treated wood board waste, J. Anal. Appl. Pyrolysis. 85 (2009) 171-183. http://doi.org/10.1016/j.jaap.2008.11.014.

[7] T.Q. Hu, Characterization of Lignocellulosic Materials, Blackwell Publishing Ltd, Oxford, 2008.

[8] T. Kuppens, P. Rafiaani, K. Vanreppelen, J. Yperman, R. Carleer, S. Schreurs, T. Thewys, S. Van Passel, Combining Monte Carlo simulations and experimental design for incorporating risk and uncertainty in investment decisions for cleantech: a fast pyrolysis case study, Clean Technol. Environ. Policy. 20 (2018) 1195-1206. http://doi.org/10.1007/s10098-018-1543-1.

[9] K. Vanreppelen, S. Vanderheyden, T. Kuppens, S. Schreurs, J. Yperman, R. Carleer, J. Yperman, R. Carleer, Activated carbon from pyrolysis of brewer spend grain: production and adsorption properties, Waste Manag. Res. 32 (2014) 634-645. http://doi.org/10.1177/0734242X14538306.

[10] S. Nizamuddin, H.A. Baloch, G.J. Griffin, N.M. Mubarak, A.W. Bhutto, R. Abro, S.A. Mazari, B.S. Ali, An overview of effect of process parameters on hydrothermal carbonization of biomass An overview of e ff ect of process parameters on hydrothermal carbonization of biomass, Renew. Sustain. Energy Rev. 73 (2017) 1289-1299. http://doi.org/10.1016/j.rser.2016.12.122.

[11] T. Kan, V. Strezov, T.J. Evans, Lignocellulosic biomass pyrolysis : A review of product properties and effects of 


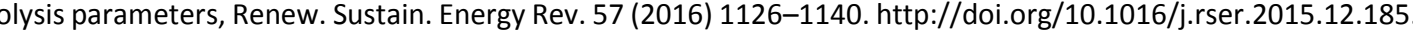
S. Wanga, G. Daia, H. Yangb, Z. Luo, Lignocellulosic biomass pyrolysis mechanism : A state-of-the-art review, Prog. Energy Combust. Sci. 62 (2017) 33-86. http://doi.org/10.1016/j.pecs.2017.05.004.

[13] N.L. Panwar, R. Kothari, V. V Tyagi, Thermo chemical conversion of biomass - Eco friendly energy routes, Renew. Sustain. Energy Rev. 16 (2012) 1801-1816. http://doi.org/10.1016/j.rser.2012.01.024.

[14] J. Li, J. Dai, G. Liu, H. Zhang, Z. Gao, J. Fu, Y. He, Y. Huang, Biochar from microwave pyrolysis of biomass: A review, Biomass and Bioenergy. 94 (2016) 228-244. http://doi.org/10.1016/j.biombioe.2016.09.010.

[15] Y. Zhang, P. Chen, S. Liu, P. Peng, M. Min, Y. Cheng, E. Anderson, N. Zhou, L. Fan, C. Liu, G. Chen, Y. Liu, H. Lei, B. Li, R. Ruan, Effects of feedstock characteristics on microwave-assisted pyrolysis - A review, Bioresour. Technol. 230 (2017) 143-151. http://doi.org/10.1016/j.biortech.2017.01.046.

[16] S. Shiung, R. Keey, C. Kui, H.A. Chase, Catalytic microwave pyrolysis of waste engine oil using metallic pyrolysis char, "Applied Catal. B, Environ. 176-177 (2015) 601-617. http://doi.org/10.1016/j.apcatb.2015.04.014.

[17] M.J. Hervan, Q. Bu, J. Liang, Y. Liu, H. Mao, A. Shi, H. Lei, R. Ruan, A review of catalytic microwave pyrolysis of lignocellulosic biomass for value-added fuel and chemicals, Bioresour. Technol. 230 (2017) 112-121. http://doi.org/10.1016/j.biortech.2017.01.059.

[18] S. Gao, K. Hoffman-Krull, A.L. Bidwell, T.H. DeLuca, Locally produced wood biochar increases nutrient retention and availability in agricultural soils of the San Juan Islands, USA, Agric. Ecosyst. Environ. 233 (2016) 43-54. http://doi.org/10.1016/j.agee.2016.08.028.

[19] L.D. Burrell, F. Zehetner, N. Rampazzo, B. Wimmer, G. Soja, Long-term effects of biochar on soil physical properties, Geoderma. 282 (2016) 96-102. http://doi.org/10.1016/j.geoderma.2016.07.019.

[20] J.L.S. Joseph, Biochar for Environmental Management: Science and Technology, second ed., earthscan, London, 2015.

[21] J. Maggen, R. Carleer, J. Yperman, A. De Vocht, S. Schreurs, G. Reggers, E. Thijsen, Biochar Derived from the Dry, Solid Fraction of Pig Manure as Potential Fertilizer for Poor and Contaminated Soils, 6 (2017) 167-184. http://doi.org/10.5539/sar.v6n2p167.

[22] C. Santín, S.H. Doerr, A. Merino, T.D. Bucheli, R. Bryant, P. Ascough, X. Gao, C.A. Masiello, Carbon sequestration potential and physicochemical properties differ between wildfire charcoals and slow-pyrolysis biochars, Nat. Sci. Reports. 7 (2017) 1-11. http://doi.org/10.1038/s41598-017-10455-2.

[23] S.D.A. Joseph, Y.A. Lin, P.A. Munroe, C.H.A. Chia, J.C. Hook, An investigation into the reactions of biochar in soil, Aust. J. Soil Res. 48 (2010) 501-515. http://doi.org/10.1071/SR10009.

[24] R. Luque, J.A. Menendez, A. Arenillasb, J. Cot, Microwave-assisted pyrolysis of biomass feedstocks: the way forward ?, Energy Environ. Sci. 5 (2012) 5481-5488. http://doi.org/10.1039/c1ee02450g.

[25] K. Smets, P. Adriaensens, G. Reggers, S. Schreurs, R. Carleer, J. Yperman, Flash pyrolysis of rapeseed cake : Influence of temperature on the yield and the characteristics of the pyrolysis liquid, J. Anal. Appl. Pyrolysis. 90 (2011) 118-125. http://doi.org/10.1016/j.jaap.2010.11.002.

[26] W. Yunpu, D.A.I. Leilei, F.A.N. Liangliang, S. Shaoqi, L.I.U. Yuhuan, Review of microwave-assisted lignin conversion for renewable fuels and chemicals, J. Anal. Appl. Pyrolysis. 119 (2016) 104-113. http://doi.org/10.1016/j.jaap.2016.03.011.

[27] H. Xiao, H. Peng, S. Deng, X. Yang, Y. Zhang, Y. Li, Preparation of activated carbon from edible fungi residue by microwave assisted $\mathrm{K} 2 \mathrm{CO} 3$ activation - Application in reactive black 5 adsorption from aqueous solution, Bioresour. Technol. 111 (2012) 127-133. http://doi.org/10.1016/j.biortech.2012.02.054.

[28] Y. Fernández, J.A. Menéndez, Influence of feed characteristics on the microwave-assisted pyrolysis used to produce syngas from biomass wastes, J. Anal. Appl. Pyrolysis. 91 (2011) 316-322. http://doi.org/10.1016/j.jaap.2011.03.010.

[29] E. Antunes, M. V Jacob, G. Brodie, P.A. Schneider, Microwave pyrolysis of sewage biosolids : Dielectric properties, microwave susceptor role and its impact on biochar properties, J. Anal. Appl. Pyrolysis. 129 (2018) 93-100. http://doi.org/10.1016/j.jaap.2017.11.023.

[30] A. Cross, S.P. Sohi, A method for screening the relative long-term stability of biochar, GCB Bioenergy. 5 (2013) 215220. http://doi.org/10.1111/gcbb.12035.

[31] A. V Mcbeath, R.J. Smernik, M.P.W. Schneider, M.W.I. Schmidt, E.L. Plant, Determination of the aromaticity and the degree of aromatic condensation of a thermosequence of wood charcoal using NMR, Org. Geochem. 42 (2011) 11941202. http://doi.org/10.1016/j.orggeochem.2011.08.008.

[32] J. Mao, K. Schmidt-rohr, G. Davies, E.A. Ghabbour, Quantitative Characterization of Humic Substances by Solid-State Carbon-13 Nuclear Magnetic Resonance, Soil Sci. 64 (2000) 873-884. http://doi.org/10.2136/sssaj2000.643873x.

[33] V.L. Budarin, P.S. Shuttleworth, M. De, T.J. Farmer, M.J. Gronnow, L. Pfaltzgraff, D.J. Macquarrie, J.H. Clark, The potential of microwave technology for the recovery, synthesis and manufacturing of chemicals from bio-wastes, Catal. Today. 239 (2015) 80-89. http://doi.org/10.1016/j.cattod.2013.11.058.

[34] P. Shuttleworth, V. Budarin, M. Gronnow, J.H. Clark, R. Luque, Low temperature microwave-assisted vs conventional pyrolysis of various biomass feedstocks, J. Nat. Gas Chem. 21 (2012) 270-274. http://doi.org/10.1016/S10039953(11)60364-2.

[35] M. Ondrej, V. Budarin, M. Gronnow, K. Crombie, P. Brownsort, E. Fitzpatrick, P. Hurst, Microwave and slow pyrolysis biochar - Comparison of physical and functional properties, J. Anal. Appl. Pyrolysis. 100 (2013) 41-48. http://doi.org/10.1016/j.jaap.2012.11.015. 
[36] Z. Hu, X. Ma, C. Chen, A study on experimental characteristic of microwave-assisted pyrolysis of microalgae, Bioresour. Technol. 107 (2012) 487-493. http://doi.org/10.1016/j.biortech.2011.12.095.

[37] X. Zhao, Z. Song, H. Liu, Z. Li, L. Li, C. Ma, Microwave pyrolysis of corn stalk bale : A promising method for direct utilization of large-sized biomass and syngas production, J. Anal. Appl. Pyrolysis. 89 (2010) 87-94. http://doi.org/10.1016/j.jaap.2010.06.001.

[38] K.Y. Foo, B.H. Hameed, Factors affecting the carbon yield and adsorption capability of the mangosteen peel activated carbon prepared by microwave assisted $\mathrm{K}_{2} \mathrm{CO}_{3}$ activation, Chem. Eng. J. 180 (2012) 66-74. http://doi.org/10.1016/j.cej.2011.11.002.

[39] D.W. McKee, Mechanisms of the alkali metal catalysed gasification of carbon, Fuel. 62 (1983) 170-175. http://doi.org/10.1016/0016-2361(83)90192-8.

[40] K.Y. Foo, B.H. Hameed, Mesoporous activated carbon from wood sawdust by $\mathrm{K}_{2} \mathrm{CO}_{3}$ activation using microwave heating, Bioresour. Technol. 111 (2012) 425-432. http://doi.org/10.1016/j.biortech.2012.01.141.

[41] X. Zhang, K. Rajagopalan, H. Lei, An overview of a novel concept in biomass pyrolysis : microwave irradiation, Sustain. Energy Fuels. 1 (2017) 1664-1699. http://doi.org/10.1039/c7se00254h.

[42] K.Y. Foo, B.H. Hameed, Preparation, characterization and evaluation of adsorptive properties of orange peel based activated carbon via microwave induced $\mathrm{K}_{2} \mathrm{CO}_{3}$ activation, Bioresour. Technol. 104 (2012) 679-686. http://doi.org/10.1016/j.biortech.2011.10.005.

[43] D.J. Macquarrie, J.H. Clark, E. Fitzpatrick, The microwave pyrolysis of biomass, Biofuels, Bioprod. Biorefining. 6 (2012) 549-560. http://doi.org/10.1002/bbb.

[44] A. V Mcbeath, R.J. Smernik, Variation in the degree of aromatic condensation of chars, Org. Geochem. 40 (2009) 1161-1168. http://doi.org/10.1016/j.orggeochem.2009.09.006.

[45] N.G. Evans, M.G. Hamlyn, Alkali Metal and Alkali Earth Carbonates at Microwave Frequencies, I: Dielectric Properties, J. Microw. Power Electromagn. Energy. $33 \quad$ (1998) 24-26. http://doi.org/10.1080/08327823.1998.11688355.

[46] Andrea Polle; Günter Müller; Christian Schöpper; Huber Vos; Alireza Kharazipour, FTIR-ATR spectroscopic analyses of changes in wood properties during particle- and fibreboard production of hardand softwood trees, Bioresources. 4 (2009) 49-71. http://doi.org/10.15376/biores.4.1.49-71.

[47] D.D. and B.H. Mizi Fan, Fourier Transform Infrared Spectroscopy for Natural Fibres, in: S. Salih, Fourier Transform Materials Analysis, Intech, Rijeka, 2012, pp. 45-67. http://doi.org/10.5772/35482.

[48] C.G. Boeriu, D. Bravo, R.J.A. Gosselink, J.E.G. Van Dam, Characterisation of structure-dependent functional properties of lignin with infrared spectroscopy, Ind. Crops Prod. $20 \quad$ (2004) 205-218. http://doi.org/10.1016/j.indcrop.2004.04.022.

[49] Y. Cai, H. Qi, Y. Liu, X. He, Sorption/Desorption Behavior and Mechanism of $\mathrm{NH}^{4+}$ by Biochar as a Nitrogen Fertilizer Sustained-Release Material, J. Agric. Food Chem. 64 (2016) 4958-4964. http://doi.org/10.1021/acs.jafc.6b00109.

[50] Y. Liu, Z. He, M. Uchimiya, Comparison of Biochar Formation from Various Agricultural By-Products Using FTIR Spectroscopy, Mod. Appl. Sci. 9 (2015) 246-253. http://doi.org/10.5539/mas.v9n4p246.

[51] M. Tatzber, M. Stemmer, H. Spiegel, C. Katzlberger, G. Haberhauer, A. Mentler, M.H. Gerzabek, FTIR-spectroscopic characterization of humic acids and humin fractions obtained by advanced $\mathrm{NaOH}, \mathrm{Na}_{4} \mathrm{P}_{2} \mathrm{O}_{7}$, and $\mathrm{Na}_{2} \mathrm{CO}_{3}$ extraction procedures, J. Plant Nutr. Soil Sci. 170 (2007) 522-529. http://doi.org/10.1002/jpln.200622082.

[52] P. Adriaensens, L. Storme, R. Carleer, J. Gelan, Comparative Morphological Study of Poly ( dioxolane )/ Poly ( methyl methacrylate ) Segmented Networks and Blends by ${ }^{13} \mathrm{C}$ Solid-State NMR and Thermal Analysis, Macromolecules. 35 (2002) 3965-3970. http://doi.org/10.1021/ma0117763.

[53] B. Ottenbourgs, P. Adriaensens, R. Carleer, D. Vanderzande, J. Gelan, Quantitative carbon-13 solid-state n.m.r. and FT-Raman spectroscopy in novalac resins, Polymer. 39 (1998) 5293-5300. http://doi.org/10.1016/S00323861(97)10283-X.

[54] C.E. Brewer, K. Schmidt-rohr, J.A. Satrio, R.C. Brown, Characterization of Biochar from Fast Pyrolysis and Gasification Systems, Environ. Prog. Sustain. Energy. 28 (2009) 386-396. http://doi.org/10.1002/ep.

[55] C.E. Brewer, Y. Hu, K. Schmidt-rohr, T.E. Loynachan, D.A. Laird, R.C. Brown, Extent of Pyrolysis Impacts on Fast Pyrolysis Biochar Properties, J. Environ. Qual. 41 (2012) 1115-1122. http://doi.org/10.2134/jeq2011.0118.

[56] A. V Mcbeath, R.J. Smernik, E.S. Krull, J. Lehmann, The influence of feedstock and production temperature on biochar carbon chemistry: A solid-state ${ }^{13} \mathrm{C}$ NMR study, Biomass and Bioenergy. 60 (2014) 121-129. http://doi.org/10.1016/j.biombioe.2013.11.002.

[57] Kyle Crombie; Ondrej Masek; Saran P. Sohi; Peter Brownsort; Andrew Cross, The effect of pyrolysis conditions on biochar stability as determined by three methods, BioEnergy. 5 (2013) 122-131. http://doi.org/10.1111/gcbb.12030.

[58] K. Jindo, H. Mizumoto, Y. Sawada, T. Sonoki, Physical and chemical characterization of biochars derived from agricultural residues, Biogeosciences. 11 (2014) 6613-6621. http://doi.org/10.5194/bg-11-6613-2014. 